\title{
REFLEXIONES SOBRE LA APARICIÓN DE NUEVOS PROGRAMAS EN LA ARQUITECTURA DECIMONÓNICA EN MÉXICO ${ }^{1}$
}

\section{Por Fausto Ramirez}

La arquitectura decimonónica es, sin duda, la porción menos estudiada y comprendida de la historia de este arte en México. No se debe esto solamente a lo que se llama la "ley de las generaciones" en el gusto artístico, es decir, la aversión que suele sentirse hacia lo producido por los antecesores inmediatos. Sobre la arquitectura decimonónica pesan, además, rencores y anatemas. El rencor de los entusiastas del arte virreinal, que no perdonan al XIX las destrucciones de tantas joyas barrocas. El anatema pronunciado, muchas veces a la ligera, por los políticos e historiadores posrevolucionarios sobre el régimen porfirista y que pareciera proyectar su sombra ominosa sobre el arte coetáneo.

Todo esto ha dado por resultado una falta de interés generalizada por estudiar a fondo y apreciar el arte decimonónico. Al revisar la bibliografía de estudios existentes sobre la arquitectura del siglo XIx, de inmediato salta a la vista su escasez y aun, en algunos de los contados ejemplos asequibles, lo inadecuado o incompleto del tratamiento del tema.

Si tomamos los panoramas generales que del arte moderno y contemporáneo trazaran investigadores como Justino Fernández o Raquel Tibol ${ }^{2}$ (en obras que, desde otro punto de vista, han constituido las primeras cartas de marear, indispensables para adentrarse en estos ignotos parajes), nos encontramos, al repasar lo escrito sobre la arquitectura decimonónica, que se limitan a destacar, primero, algunas obras de la instauración del estilo neociásico en México (en referencia à sus más connotados representantes, en la capital y el Bajío, vale decir Tolsá y Tresguerras); más adelante, los arquitectos que, al promediar el siglo, vinieron a

1 Este artículo es una versión modificada de una conferencia dictada en la Alianza Francesa de la ciudad de Méxiç, el 9 de noviembre de 1977. La imposibilidad de ilustrar gráficamente el texto con la abundancia de ejemplos que es factible mostrar en una conferencia, constituye una seria desventaja del trabajo escrito frente a la expoposición oral. He tratado de subsanarla por la adición de notas que consignan ejemplos particularmente relevantes. A menos que se especifique en contratio, las obras mencionadas a lo largo del texto y las notas se encuentran en la ciudad de México.

2 Fernández, Justino: Arte moderno y contemporáneo de México. México: UNAM, 1952. Hay una reedición de 1967, en que se desglosó la parte correspondiente al siglo xIx, publicada con el título: El arte del siglo XIX en México, México, UNAM, Cito de esta edición. 'Tibol, Raquel: Historia general del arte mexicano: época moderna y contemporánea. México, Editorial Hermes, 1964. 
ocuparse de la cátedra correspondiente en la Academia capitalina de San Carlos (es decir, Lorenzo de la Hidalga y Javier Cavallari); finalmente, se refieren a la intensa actividad constructiva durante el porfiriato y espigan unas cuantas muestras, todas de la ciudad de México, especialmente las más ambiciosas, pronunciando de paso comentarios acerca del "afrancesamiento" o "europeísmo" del régimen, el carácter indiscriminado de la copia de modelos extranjeros, el relegamiento de los arquitectos locales en favor de los foráneos, etcétera, todo lo cual es verdadero, pero representa sólo una pequeña parte de la verdad.

El término de "anacrónico-exótica" que acuñara José Villagrán García ${ }^{3}$ para caracterizar tipologicamente la arquitectura finisecular, me parece muy revelador de la poca simpatía y el escaso aprecio que solía (y suele aún) despertar este aspecto de nuestra arquitectura y, también, de las razones de fondo que impedían valorarla debidamente: anacrónica y exótica, es decir, doblemente ajena, en apariencia, a nuestra sensibilidad actual y, de algún modo, falsa e indeseable.

La impresión que queda al leer estos trabajos es de relativa pobreza en el quehacer edilicio decimonónico, que no puede compararse con lo hecho en los siglos virreinales, ni en cantidad, ni en calidad, ni tampoco en concordancia con un supuesto ethos, modo de ser o sensibilidad estética del mexicano. Porque, o bien el escritor demuestra una declarada simpatía por el clasicismo y una total incomprensión del eclecticismo, como en el caso de Justino Fernández; ${ }^{4}$ o bien, como lo hace Raquel Tibol, se insinúa que el pueblo mexicano pareciera amar connaturalmente el barroco, razón por la cual "miró con hostilidad" su sustitución por las formas neoclásicas, sólo aceptadas y bien comprendidas por las clases cultas y poderosas, y que en Ios "pocos casos" en que la arquitectura popular adoptó dichas formas nuevas lo hizo "en forma superficial, copiando la apariencia". 5

En la medida en que los textos mencionados prescindian de toda arquitectura que no fuera la académica o culta; dejaban prácticamente

3 Villagrán García, José. "Programa de 62 años de arquitectura mexicana contemporánea (1900-1962)", México. Cuadernos de Arquitectura núm. 10, octubre de 1963. INBA, pp. I $V \cdot V$ y XII y xv.

4 El doctor Fernández no escatima pullas para lo que él llama "romanticismo académico": "locuritas románticas..., locuritas goticistas, renacentistas", etcétera $\left(o, c_{\text {: }}\right.$ : 179) . Fuera del clasicismo y del barroco "puristas" todo se halla desvixtuado, según él a finales del siglo.

Con todo, se muestra favorable al art nouveau, del que se declara partidario incondicional.

5 Tibol, o. c. 11. 
fuera todo lo realizado allende la ciudad de México; no se aplicaban a un estudio de los nuevos programas o soluciones espaciales, enteramente inéditos en el pais, que hubo de resolver el arquitecto decimonónico; y no abordaban los fenómenos del neoclasicismo y, sobre todo, el eclecticismo con la perspectiva estética adecuada: en esa misma medida, digo, su tratamiento del tema deja mucho que desear y, por incompleto $e$ inadecuado, produce una impresión totalmente falseada $y$, por lo mismo, engañosa. ${ }^{6}$

Durante muchos años, la bibliografía decimonónica sólo se enriqueció con trabajos parciales, artículos o ensayos breves, como los de Francisco de la Maza, uno de los investigadores más preocupados por rescatar y acentuar los valores de este siglo desdeñado; ${ }^{7}$ algunos trabajos de Elisa García Barragán ${ }^{8}$ o de Antonio Bonet Correa, ${ }^{9}$ de los primeros en marcar la importancia de la arquitectura porfiriana en la provincia. O bien, con estudios monográficos de obras y arquitectos destacados, escritos por Víctor Manuel Villegas o Salvador Pinoncelly. ${ }^{10}$

La verdadera gran ampliación en nuestro conocimiento del tema se la debemos a Israel Katzman, quien, primero en la parte inicial de

6 El propio Justino Fernández advertía (1967): "Es necesario hacer una investigación especial de la arquitectura del siglo XIX" (o.c.: I21), y hacía mención, en nota, de los trabajos que por aquel entonces realizaba Katzman (ibid., nota 215, p. 223).

7 De la enorme bibliografía de Francisco de la Maza (cf. Anales del Instituto de Investigaciones Estéticas, UNAM, xI, 41, 1972, p. 149-174) destaco los siguientes títulos: "El palácio de gobierno de San Luis Potosi", Estilo, Revista de Cultura, San Luis Potosí, núm. 3, 1946, p. 149-155; 'Algunas obras desconocidas de Manuel Tolsá", Anales del IIE, IV, 14, 1946, p. 33-54; "Dibujos y proyectos de Tresguerras", Anales IIE, v, 18, 1950, p. 27-33; "La tumba de Tresguerras", Anales IIE, v, 19, 1951, p. 105-120. "El urbanismo neoclásico de Ignacio de Castera", Anales IIE, 22, 1954, p. 93-101. "Sobre arquitectura art nouveau", Anales IIE, vIr, 26, 1957, p. 5-37; "En el segundo centenario de Tresguerras", Anales IIE, viII, 29, 1960, p. p. 9-14; "Otra vez Tresguerras", Anales IIE, vIIr, 32, 1963, p. 53-58; Del neoclísico al art nouveau y primer viaje a Europa. México, Secretaría de Educación Pública (Sepsetentas 150), 1974. De la Maza también editó, prologándolos y anotándolos, los Ocios literarios, de Francisco Eduardo Tresguerras. México, UNAM, Estudios y Fuentes de Aite en México, IIE, 1962.

8 García Barragán, Elisa: 'Supervivencias mudéjares y presencias orientalistas en la arquitectura mexicana", Anales IIE, xIII, 45, 1976, p. 137-146; "Lorenzo de la Hidalga", en Del arte. Homenaje a Justino Fernández. México, UNAM, 1977, p. 203-218.

9 Bonet Correa, Antonio: La arquitectura de la época porfiriana en México. Murcia, Publicaciones de la Universidad, 1966 "La arquitectura porfiriana", Revista de la Universidad Complutense de Madrid, xxrr, 86, 1973, p. 79.88.

10 Villegas, Víctor Manuel: Tresguerras, arquitecto de su tiempo. México, Diana, 1964; El panteón romántico de Guadalajara. México, 1969; "Refugio Reyes, gran arquitecto", Revista de Bellas Artes, enero-diciembre de 1972, p. 10-44. Arquitectura 
su "Arquitectura Mexicana Contemporánea: precedentes y desarrollo", y luego en su obra fundamental Arquitectura del siglo XIX en México, ${ }^{11}$ inició el estudio genuinamente contemporáneo del problema, rebasando las anteriores limitaciones de método y perspectiva.

No procupaba a Katzman, en el momento de escribir su texto, teorizar en abstracto acerca del valor de dicha arquitectura. Su propósito explícito fue consignar la existencia y proceder al registro fotográfico, clasificación y catalogación de las obras decimonónicas que todavía se conservan, previendo su fatal destrucción en el futuro. Katzman estudia sucintamente las condiciones de formación del arquitecto académico (sistema educativo, marcos teóricos) y analiza el contexto del desarrollo urbano en que las obras hubieron de inscribirse, pero la parte medular del texto está dedicada al estudio morfológico de la arquitectura mexicana del siglo $\mathrm{xIx}$, con el fin de proponer una tipología clasificatoria.

Basta con echar una ojeada al rico material fotográfico que acompaña e ilustra el texto, y a la nómina final de arquitectos y obras (improbo y útil trabajo de recopilación), para comprobar la extraordinaria riqueza de este momento de la historia arquitectónica de nuestro país.

Por desgracia, lo publicado por Katzman no es sino una parte de lo que habría de ser un estudio cabal del tema, por completarse en volúmenes subsecuentes, dedicados al estudio especifico de los programas arquitectónicos desglosados y las soluciones que se dio a los mismos.

Antes de comentar sobre las ventajas que tal método ofrece, quisiera redondear estas someras referencias bibliográficas, y aludir a los trabajos recientes emprendidos por Sonia Lombardo, auspiciados por el INAH, en su Dirección de Estudios Históricos: en contraposición al intento totalizador de Katzman, esta investigadora se ha propuesto el análisis minucioso y exhaustivo de edificaciones concretas, elegidas por su representatividad ejemplar. Con gran rigor ha buscado y descubierto, en la base económica e histórica, los fundamentos y finalidades de las

de Rejugio Reyes. México, Imprenta Madero, 1974; Pinoncelly, Salvador, Manuei Tolsá, arquitecto y escultor. México, Secretaría de Educación Pública (Cuadernos de Lectura Popular 190), 1969. De Tolsá existe otra monografía reciente: Almela y Vives, Francisco y Antonio Igual Ubeda: El arquitecto y escultor Manuel Tolsá, 1757-1816. Valencia, Institución Alfonso el Magnánimo, Diputación Provincial de Valencia, 1950 .

Fernández, Justino et al: El palacio de mineria "México, UNAM, 1951; El Hospicio Cabañas. México, Editorial Jus, 1971.

11 Katzman, Issael, Arquitectura contemporánea mexicana. Precedentes y desarrollo. México, Memorias VIII, INAH, 1963. Arquitectura del siglo XIX en México, tomo $\mathrm{I}_{\text {. }}$ México, UNAM, 1973. 
soluciones estructurales planteadas por los arquitectos, con resultados de primer orden. ${ }^{12}$

Volviendo al método que se proponía seguir Katzman (y que, por desgracia, no ha podido llevar a término), es decir, estudiar las obras decimonónicas agrupadas por tipos constructivos, tengo para mí que es la alternativa más viable para mejor esclarecer la verdadera importancia que dicha arquitectura, considerada en su conjunto, tuvo y sigue teniendo para nuestro siglo.

Ya para entrar plenamente en materia, debo aclarar de principio lo que, en mi opinión, abarca el concepto "arquitectura decimonónica". En la historia del arte, las longitudes cronológicas absolutas rara vez coinciden con divisiones significativas de los fenómenos estilísticos. Así ocurre precisamente con el término en cuestión: nuestro siglo xrx es un siglo de cerca de ciento cincuenta años. Se inicia durante la fase final del virreinato, con el rechazo del barroco florido y la adopción de un sobrio clasicismo, cuando corría el último cuarto del siglo xviri; y viene a concluir, no con la partida de Porfirio Díaz en el "Ipiranga" -que en lo arquitectónico no da como resultado inmediato cambio sustancial alguno-, sino con el abandono del estilo ecléctico imperante hasta la década de 1920 a 1930, en favor de la desnuda arquitectura funcionalista - la más ornada pero no menos funcional que propiciara el Art Déco.

$\mathrm{Y}$ conste, también de principio, que digo "estilo ecléctico", porque, en contra de lo que solía pensarse, el eclecticismo, es decir, la deliberada imitación simultánea de las distintas soluciones formales que ofrecen los estilos de épocas pasadas (desde la morfología clásica hasta las variantes barrocas, con posibilidad de espigar también fuera del ámbito de la cultura europea para admitir estructuras formales árabes, hindúes o chinescas), el eclecticismo, repito, corresponde a un ethos cultural perfectamente definible y expresa todo un sentido de la historia y de la vida, que posibilita erigirlo a la categoría de estilo.

Por un lado, el eclecticismo es el correlato (y ei reflejo) de la conciencia historicista que, desarrollada en el pensamiento europeo de los siglos xvIII y xIX, se traduce en un respetuoso interés por estudiar las culturas de otros tiempos, valoradas conforme a sus propias premisas, asumiendo el aporte de los siglos pretéritos en la constitución del presente.

Pero esta conciencia de lo histórico no fue asumida como dato pura-

12 Lombardo de Ruiz, Sonia, "La Ciudadela: ideologia y estilo en la arquitectura del siglo xvm". México, Cuadernos de Trabajo del Departamento de Investigaciones Históricas, INAH, núm. 12, febrero de 1976. 
mente intelectual; se la vivió también a nivel entrañable, afectivo. La experiencia del pasado se cargó de asociaciones emocionales, favoreciendo su recreación estética, su vivencia poética. Literatura, pintura, arquitectura, atestiguan desde el último cuarto del siglo xvir este anhelo de revivir creativamente el pasado, de proyectarlo en el presente, sea para mejor iluminarlo (como en la búsqueda de las raíces culturales, nacionales, impulsada por el romanticismo), sea por el mero afán de evocar la poesía de las cosas idas.

Si no reconocemos la potencialidad de las formas artísticas para estimular esta vivencia poética de las culturas pretéritas, difícil será comprender y gustar el eclecticismo.

Por otra parte, la referencia al pasado desempeñó, particularmente en la arquitectura, un papel importante de representación ideológica. El prestigio de los símbolos tradicionales perdura mucho más allá de su vida natural, es decir, más allá de la vida de la cultura que les dio origen.

Las formas simbólicas sancionadas por el uso secular se cargan, en el pensamiento visual de una colectividad, de determinadas connotaciones vinculadas a las jerarquias que se han servido de ellas para sus fines de expresión y representación ideológicas. Merced a esto, las formas suscitan asociaciones, casi connaturales a su uso, en la mentalidad de quien las contempla. Su utilidad como elemento de enaltecimiento social y de confirmación jerárquica, fue presto descubierta por los grupos emergentes que ascendieron al poder con las revoluciones que inauguran el mundo moderno.

Como es de todos sabido, la burguesía se eleva vigorosamente a lo largo del siglo xvin y logra definirse, finalmente, como el estrato rector de los destinos históricos de Occidente. Sustentada, en lo económico, en el desarrollo de las nuevas formas de producción industrial (máquinas impulsadas por energía térmica y operadas por obreros concentrados en extensas instalaciones productivas); apoyada, para lo político, en el ideal del gobierno parlamentario y representativo de los intereses democráticos (léase, del grupo que controla los medios de producción); espoleada por la posibilidad de movilidad y ascenso social, al quedar abiertos los caminos al talento en un clima de libre competencia; y sosteniendo y validando todo esto mediante un sistema filosófico esencialmente crítico, antitradicional y racionalista (llámese pensamiento ilustrado o positivismo), la burguesía no sólo trepó al poder, sino que señaló nuevos derroteros a la vida y al pensamiento humano para los siglos venideros. 
Nueva poseedora de la autoridad, la burguesía, para hacer sensible y entretejer la idea de su poder en la mente de las gentes, se sirvió precisamente de los símbolos y las formas que, en el arte y la arquitectura, crearan las jerarquias que ella había venido a sustituir.

En efecto, una arquitectura basada en los ejemplos prestigiados por la tradición provocaba lógicamente asociaciones con las imágenes familiares de autoridad y respetabilidad, suscitando el reconocimiento y la admirativa sumisión requeridos por el nuevo grupo en el poder. Por supuesto, no todo fue imitación esclavizada. Con auténtica genialidad, el siglo XIx fue capaz de adaptar los viejos símbolos a las necesidades actuales, pero acertó también a crear nuevos símbolos y aprendió finalmente a utilizar expresiva y eficazmente los recursos estructurales posibilitados por la producción industrial (el hierro, el vidrio y, posteriormente, el concreto armado).

No es casual que haya afirmado antes que la arquitectura decimonónica comienza en el siglo xvin, con la reacción antibarroca que auspicia el neoclasicismo. La lúcida sobriedad neoclásica fue tomada como signo de los tiempos nuevos, en la crisis de la autoridad tradicional.

Neoclasicismo y pensamiento ilustrado estuvieron estrechamente vinculados, como se encargara de señalar, hace muchos años, para el arte mexicano, Justino Fernández. ${ }^{13}$

Más aún, pensamiento ilustrado y racionalismo son, en cierto modo, sinónimos. El afán de someterlo todo a examen, cuidando de no aceptar simple y llanamente las ideas recibidas en virtud de su vetustez venerable, sino sólo como resultado del dictamen de la razón, árbitro supremo y exclusivo, fue proyectado a todas las esferas de la vida humana, incluidos (y de manera preponderante) los aspectos más pragmáticos y concretos de la misma. Procedimiento que, en la coyuntura de las radicales modificaciones producidas, en lo político-social por la Revolución Francesa y, en lo económico, por la Revolución Industrial, hubo de dar por consecuencia una alteración radical en las formas de la vida del hombre.

Sobrevino una particularización, una delimitación especializada en las actividades y funciones de la existencia, como resultado de una rigurosa definición de su diversa significatividad para el individuo y la sociedad.

Así se fueron compartimentando y diferenciando, con plena especificidad, las distintas esferas o jurisdicciones de la actividad y el ser del

13 F'ernández, o. c.: 2-12. 
hombre: lo religioso, lo político, lo ético, lo estético, lo pragmático en sus diversas modalidades, llevando a su término un proceso que, de hecho, habiase iniciado a finales de la Edad Media y con el Renacimiento.

A cada uno de estos ámbitos de lo humano, hubo de corresponder necesariamente la definición de un espacio propicio y representativo donde desarrollar las actividades pertinentes.

Nunca antes el arquitecto occidental había enfrentado la exigencia de resolver, de manera especifica y funcional, la construcción de tantos y tan diferentes espacios para las más disímbolas acciones y situaciones de la existencia humana.

Con la instauración de la modernidad, se define una amplia gama de programas nuevos, para algunos de los cuales difícilmente podrían hallarse antecedentes. Dicho con las palabras escritas en 1886 por Henry van Brunt: "El arquitecto, a lo largo de su profesión, se ve llamado a levantar edificios para todos los propósitos concebibles, la mayoría de los cuales tienen que cumplir exigencias nunca antes suscitadas en la historia... Toda suerte de edificios para ferrocarriles; iglesias con salas de recepción, cocinas y salones de convivencia social; hoteles de una magnitud jamás imaginada; bibliotecas públicas que requieren servicios sustancialmente diferentes a los de sus predecesoras; edificios de oficinas y de función comercial, como nunca los requirieran las anteriores circunstancias de la vida profesional y mercantil; escuelas y colegios cuyas instalaciones difieren considerablemente de los venerables ejemplos de Oxford y Cambridge; pistas de patinaje, teatros, pabellones de exposiciones de vasta amplitud, casinos, cárceles, ayuntamientos, music halls, para satisfacer las complejas circunstancias de la sociedad humana... Sobre la base de consideraciones eminentemente prácticas, de las plantas deben derivar los alzados, para los cuales (si han de ser trazados con honestidad) no puede haber precedentes en la historia de la arquitectura." 14

Estas palabras, enunciadas por uno de los arquitectos que vivieron en carne propia la experiencia, revelan el azoro mezclado de entusiasmo que provocaba la construcción moderna, y constituye también una especie de muestrario anticipado de los diversos tipos de estructuras que tuvo que crear el siglo xix, a cuya razón de ser y función específica están dedicadas las siguientes reflexiones.

14 Citado en Pevsner, Nikolaus: A History of Building Types, p. 9. Princeton University Press, Princeton, N. J. Bollingen Series xxxv, 19, 1976. 
Consideremos, en primer término, los edificios gubernamentales. El paso de las monarquías absolutas a los regímenes parlamentarios es lo que caracteriza, en lo referente a la estructura política más visible, el tránsito del antiguo régimen a la modernidad. Esto, a su vez, hubo de traducirse en una diferenciación de las estructuras arquitectónicas. El gobierno monárquico queda ligado a la imagen del palacio principesco, por ejemplo el Louvre o Versalles en el ámbito francés, o el Palacio de Oriente en Madrid. En México, lo más cercano a un palacio con asociaciones cortesanas de esta índole podría ser el de Chapultepec, que, aunque iniciado por el virrey Bernardo de Gálvez como residencia de campo, fue trasformado posteriormente y queda inextricablemente ligado, en la mente del mexicano, a la trágica figura de Maximiliano $\mathrm{y}$, más tarde, a la de Porfirio Díaz, quien hiciera del castillo casa veraniega.

Per̃o prescindiendo de este ejemplo más bien figurado que genuino, al no haber existido en Nueva España un gobierno hereditario a la manera europea, no hay tampoco ningún palacio al que se asocie este tipo de connotaciones "Existió, por supuesto, el palacio de los virreyes, residencia y sede del poder. Pero, desprovisto de aquellas asociaciones dinásticas, se consideró adecuado que, al concluix el régimen colonial, convertido en Palacio Nacional continuara siendo sede del ejecutivo, experimentando con el tiempo modificaciones y adiciones a medida que crecía el aparato burocrático y se requerían nuevos salones de recepción, reunión, etcétera. Una de las primeras modificaciones que sufriera es particularmente importante: la trasformación de una de sus salas en cámara de representantes o diputados, obra de Agustín Paz que data de 1824-1829. Mucho más tarde, durante el porfiriato, se dio a muchos de sus salones de recepción el aspecto ornamental y la disposición espacial que hoy conservan.

De lo anterior, interesa destacar, sobre todo, la necesidad experimentada de disponer de una sede para el poder legislativo.

La concepción moderna del gobierno demandaba, al menos en teoría, la separación y autonomía de los tres poderes, ejecutivo, legislativo y judicial. Para hacer asequible la idea de diversificación de las esferas del poder, fue necesario proceder a albergarlas en sendos espacios diferenciados. De ahí la preocupación por encontrar un lugar adecuado para las cámaras. Desde 1874, la de Diputados se trasladó a lo que fuera 
el Teatro de Iturbide. Destruido por un incendio, la estructura que hoy vemos data de 1910 y es obra de adaptación de Mauricio M. Campos. Sin embargo, este local sólo habría sido asiento temporal de la Cámara, de haberse llevado a término el gran proyecto porfirista del Palacio Legislativo, iniciado en 1905 según planos de Emile Bénard (1903-1904). El poder judicial no vino a encontrar asiento permanente hasta muy entrado el siglo $\mathrm{xx}$, en el curioso edificio entre funcionalista y neoclásico que proyectara, en 1935, Antonio Muñoz García. En el xix, la Suprema Corte anduvo errante por varios edificios provisionales. Conocemos un proyecto de trasformación del convento de la Enseñanza Antigua, con este propósito, que data de 1868 y no llegó a realizarse; sabemos también que ocupó en 1890 una casa en Avenida Juárez, de J. Muller, dispuesta para tal fin, ${ }^{15}$ y que el ingeniero Porfirio Diaz adoptó, para la Suprema Corte, el Palacio del Marqués del Apartado, obra de Tolsá.

Francisco de la Maza ha señalado ${ }^{16}$ que, en el siglo pasado, hubo tanto obras de creación como de adaptación y modernización de antañonas estructuras virreinales. Las razones de esto son varias, fáciles de discernir: resultaba más económico proceder a una simple alteración de la fachada y a algunas modificaciones interiores para remozar, a tono con la moda del día, el aspecto del edificio, que no levantarlo ex novo. Por efecto de la agitada sucesión en el poder de facciones políticas hostiles y las dramáticas incidencias de invasiones y restauraciones, no se contó muchas veces, durante el siglo $\mathrm{xIx}$, con los recursos suficientes para levantar una estructura nueva. La abierta especulación con la propiedad, iniciada precisamente en el periodo considerado (y en la coyuntura del ingreso del país a las condiciones modernas del capitalismo -por limitado y dependiente que haya sido el proceso--), ocasionó también la preferencia de la adaptación sobre la construcción. La enajenación de los bienes del clero, y los cambios de propiedad a ella anejos, fueron asimismo causa determinante del fenómeno.

Los cambios en la estructura política del país, acaecidos a finales del virreinato y confirmados con la Independencia (paso del sistema de intendencias al de Estados), así como la Constitución Federativa de la República Mexicana, hicieron necesaria la erección de palacios gubernamentales en las capitales estatales. Como en la capital, se trata a

15 Cf. Katzman, 1973, p. 150 (lám. 326) y 136 (lám. 273)

16 De la Maza, "Del neoclásico al art nouveau...", p. 15, 
veces de edificios creados ex novo, a veces de adaptaciones de edificios ya existentes, en especial de los enajenados al clero. ${ }^{17}$

Aspecto importante de la regimentación urbana es el ayuntamiento, sede de la autoridad local, erigida, si no en antagonismo sí por lo menos con clara conciencia de autonomía frente al poder central. Vieja tradición del medioevo que desde el primer momento se implantó en Nueva España, y fue heredada por el mundo moderno. La experiencia o señalización física de esto la tenemos en la erección de palacios municipales a lo largo y lo ancho de la República. Un ejemplo particularmente suntuoso es el Ayuntamiento de Puebla, obra del arquitecto Carlos S. Hall y del decorador Jesús Corro Soriano, que data de 18971908. Pero no sólo en las grandes capitales estatales se alzan estos edificios grandiosos. No pocas veces pequeñas cabeceras municipales también ostentan ayuntamientos cuya magnitud supera toda expectativa lógica, sólo explicable como signo del poder, a veces ausente, del pre-. sidente municipal. ${ }^{18}$

Cumple resaltar la apariencia palaciega que caracteriza a todas las construcciones consideradas hasta ahora: su monumentalidad imponente, evidenciada en las dimensiones físicas absolutas (muchos de los palacios ocupan toda una manzana o, al menos, una parte sustancial de la misma), pero también en las relativas, en sus ritmos y proporciones (uso del orden colosal en las fachadas, con columnas o pilastras que determinan pausas solemnes, ceremoniales; planteamiento del partido en torno a patios de amplias dimensiones; presencia de majestuosas escaleras y lujosos salones de recepción). El carácter palaciego se expresa también por la centralidad urbana de estos edificios: siempre o casi siempre frente a la plaza principal, presidiendo con su altiva mole la vida citadina. En esto, el siglo xIx fue simple legatario de la tradición de las ordenanzas virreinales, pero les confirió nuevo brillo. Estilísticamente, los proyectos van de la sobriedad clasicista del Palacio de Gobierno en San Luis Potosí, obra de Miguel Costansó, al neobarro. quismo del ayuntamiento poblano, tal vez el estilo más socorrido para

17 Buen ejemplo del segundo caso, el Palacio Federal de Morelia, antiguo Seminario Tridentino, sede del gobierno estatal desde 1860, Ramírez, Esperanza: Guia Artistica de Morelia, p. 32, Morelia, 1977.

18 Esto lo señaló José Manuel Caballero-Barnard, para el Estado de México, en conferencia dictada en la Universidad Iberoamericana el $1^{\text {to }}$ de marzo de 1978 , y dio los ejemplos de los palacios de Acambay, Tlalnepantla, Santiago Tianguistenco, El Oro, Tenancingo, etcétera. Efraín Castro, por su parte, advertía el mismo fenómeno en la región norte del Estado de Puebla: palacios municipales de Huauchinango, Tetela del Oro, Zacatlán (conferencia del 22 de febrero de 1978). 
los grandes palacios gubernamentales fin de siglo, por las evidentes implicaciones asociativas que evoca: se trata de un barroco a la francesá, puesto en boga en todo el ámbito occidental a partir de la amplia. ción del Louvre.

Patios, vastos salones de recepción, múltiples oficinas, ostentosas escalinatas y fachadas: estos mismos elementos constitutivos caracterizan también a los ministerios, asiento de las distintas dependencias que se fueron desglosando para atender funciones específicas, a medida que el gobierno se hacía más complejo y crecía, correlativamente, la burocracia, signo indudable de los tiempos modernos (como lo atestiguan Galdós o Kafka). Fue el porfiriato, y no por casualidad, el que confirió a las secretarías o ministerios su importancia y envergadura actuales, y el que creó también los magníficos edificios que los alojan.

No por casualidad, tampoco, se construyeron palacios tan suntuosos para secretarías vinculadas al desarrollo del país en sentido moderno, como eran las de Comunicaciones (Silvio Contri, 1902-1911), la Administración de Correos (Adamo Boari, 1902) o la Secretaría de Relaciones Exteriores, índice de la importancia que estos ramos cobraron para la vida del régimen porfiriano.

El Estado moderno, en tanto que teóricamente funda su autoridad sobre su carácter representativo de los intereses colectivos, se ve obligado a proveer al alivio de exigencias de la población antes atendidas, en gran parte, por la Iglesia. Tenemos así la construcción de obras asistenciales y de servicio, como hospitales, asilos, hospicios y cementerios.

Los edificios hospitalarios fueron obra a veces del gobierno, a veces de la iniciativa privada, lo cual en el fondo no es sino una y la misma cosa, en la medida en que el Estado representa, de hecho, los intereses de los estratos económicos que controlaban los medios de producción. ${ }^{19}$

Por supuesto, es posible plantear en otros términos el problema de la sustitución de la Iglesia por el Estado en las obras asistenciales: el Estado, en su intento de arrebatar al clero su poder y sus bienes, disfraza sus intereses so pretexto de benevolencia ilustrada y modernización racional. Tal ocurrió, por ejemplo, con la creación de los cementerios, propugnados desde las postrimerias de la Colonia por las disposiciones de Carlos III y, luego, de Carlos IV, que sólo vinieron a cobrar realidad

19 Hospicios particularmente monumentales son el Cabañas de Guadalajara (M Tolsá y José Gutiérrez, 1805-10, concluido por Manuel Gómez Ibarra, 1845) y el de Puebla (construido sobre el sitio del colegio jesuítico de San Ildefonso, destruido durante la intervención francesa). Vale la pena mencionar el Hospicio de Huérfanos de Guadalupe, Zacatecas, obra de Refugio Reyes (1905). 
en la época independiente. ${ }^{20}$ Fue largo el proceso de desarraigar la inveterada costumbre de enterrar a los muertos en los atrios y el interior de las iglesias, para hacerlo mejor en panteones construidos exprofeso a extramuros de la ciudad, ciertamente más higiénicos, en particular durante las epidemias que asolaban con gran mortandad las ciudades, todavía en el siglo pasado. Sin duda, el más bello ejemplo de cementerio romántico en México es el de Santa Paula o Belén, en Guadalajara.

El deseo de conmemorar al difunto, procurando al mismo tiempo destacar su importancia social y suministrar a los deudos una idea religiosa o filosófica que les sirviera de consuelo, llevó al desarrollo de un género importante en que arquitectos y escultores hubieron de trabajar de consuno: el monumento funerario, resuelto en múltiples y variadas formas, de la lápida al túmulo y la capilla familiar, donde la imaginación muchas veces logra imponerse sobre la reiteración monótona de la producción en serie.

El monumento funerario, cuando se erige en homenaje a algún héroe cívico (como el mausoleo de Benito Juárez, en el panteón de San Fernando), roza indudablemente con el monumento conmemorativo a secas, expresión también muy representativa del arte moderno, a partir del Siglo de las Luces.

Por supuesto, la conmemoración heroica ha sido usual a lo largo de la historia humana. La diferencia fundamental estriba en que, antes de la Ilustración, la dedicación de monumentos se reservaba a reyes y gobernantes; tenía, pues, un carácter eminentemente dinástico y no un sentido nacional.

La idea de levantar monumentos a las glorias nacionales data del siglo xvir, y tiene por sujeto conmemorable ya no únicamente gobernantes sino también pensadores, sabios, poetas, artistas... ${ }^{21}$ EI monumento se democratiza: no sólo se amplía la jerarquía social del conmemorado, sino que acentúa muchas veces el carácter humano, ya no semidivino, sagrado, de la figura representada: la condición de primus inter pares que el personaje tiene en la República moderna.

20 Ce. Staples, Anne, "La lucha por los muertos" Dialogos, El Colegio de México, XIII, 5, 1977, p. 15-20. Y, Nicolau Benito, Lourdes: La arquitectura y escultura del cementerio de San Fernando en México, tesis profesional, Departamento de Arte, Universidad Iberoamericana, 1977.

21 Los monumentos erigidos a lo largo del Paseo de la Reforma son un muestrario de la amplia gama de personajes conmemorables. Un ejemplo extraordinario de monumento a un artista se halla en Saltillo: el Monumento a Manuel Acuña, obra de Jesús Contreras. $\mathrm{Y}$ en Jamay un caso raro de conmemoración en el México decimonónico: el monumento a Pio Nono. 
El monumento es también resultado de la secularización de la cultura: el afán de celebración en la memoria de la posteridad vino a remplazar, parcialmente al menos, la búsqueda de la bienaventuranza religiosa.

Pero el monumento es, además, un claro indice de la postura ideológica del Estado que los erige: evidentemente sólo se rinde homenaje público a los personajes que simbolizan o representan ideas con las cuales el Estado quiere que se le identifique.

Con los monumentos entramos, de manera explícita, en el área que Louis Althusser designa como "aparatos ideológicos del Estado", es decir, los instrumentos de que se sirve el grupo en el poder para entretejer y consolidar en la mente de la comunidad los conceptos y los mitos que permiten la supervivencia del statu quo.

Aquí cabrian, pues, todas aquellas instituciones que se proponen la formación del individuo en cuanto ente social integrado: escuelas, museos, teatros...

Una de las preocupaciones de los ilustrados fue el fomento de la educación, como instrumento que impulse el desarrollo racional del ser humano, posibilitando la cabal expansión de sus facultades y su inserción positiva, creadora, en la colectividad. Pero junto a estas posibilidades liberadoras del concepto educativo, es indudable también que la escuela ha servido, y sirve, como instrumento reproductor de los esquemas ideológicos, como conformador del individuo dentro del enmarcamiento global (económico-político-social) en que la sociedad necesita inscribir a los miembros de sus respectivos estratos.

No es casual que el Estado moderno se haya preocupado por arrebatar, también, este poderoso instrumento de manos de la Iglesia, proclamando la educación laica y obstaculizando lo que denomina educación "confesional".

En México, la construcción de escuelas tiene una larga tradición y ha producido edificios de primer orden. Bastaría pensar, durante la Colonia, en los espléndidos colegios jesuíticos o el de las Vizcaínas. Pero precisamente a finales del virreinato se levanta una escuela que viene a representar el nuevo espíritu ilustrado frente a la estancada tradición secular: la Escuela de Minas, obra de Manuel Tolsá, cuya monumental concepción palaciega vino a simbolizar el orgullo de los poderosos mineros criollos que, frente a la rutina del régimen peninsular, parecieran afirmar. la necesidad de una reorientación racionalista por los cauces modernos, si bien fuera al menos en lo tocante al renglón que constituía la mayor 
fuente de ingresos con que la metrópoli se beneficiaba de sus colonias: el ramo de minas.

Para encontrar otros ejemplos tan magníficos de estructuras educativas, habrá que saltar a las escuelas normales construidas por todo el país durante el porfiriato, ${ }^{22}$ con un claro deseo de afirmar la importancia que el proceso educativo desempeñaba dentro del régimen. También sobresalen los grandes edificios que albergaban los institutos científicos y literarios fundados en las principales ciudades, raíz de muchas de las actuales universidades estatales. ${ }^{23}$ Por todos lados cunden las escuelas, unas más modestas, otras menos, muy representativas en su abundancia del siglo de José María Luis Mora, Gabino Barreda y Justo Sierra. ${ }^{24}$

Junto a esta riqueza contrasta la escasez o casi nulidad de edificios importantes específicamente levantados con el objeto de servir de museo o biblioteca. A diferencia de la Europa decimonónica, México no cuenta en esta línea con ninguna construcción memorable en lo que se refiere a museos de arte. Se instalaron galerías para exhibir las obras más destacadas del arte mexicano, pero esto como simple obra de adaptación en inmuebles ya existentes. Así surgieron, por ejemplo, las galerías de pintura colonial en la Academia de San Carlos (obra de Javier Cavallari) y el museo de antigüedades prehispánicas instalado dentro del bloque del Palacio Nacional, sobre la calle de la Moneda. Aunque significativas, es palmario que semejantes obras no pueden compararse con museos tan eminentes como el Altes Museum de Berlín o la Gliptoteca de Munich, ni tampoco con los grandes museos finiseculares norteamericanos, como el de Filadelfia o el Metropolitano de Nueva York. El mejor edificio museístico decimonónico construido en México alberga, no una colección de objetos artísticos, sino científicos: se trata del bello edificio del Instituto de Geología, obra de Carlos Herrera (19001906). No debemos olvidar que el de Historia Natural del Chopo, no

22 Espléndidos ejemplos en Toluca (Vicente Suárez, 1907-1910), Puebla, Guanajuato, Saltillo, Aguascalientes...

23 El Instituto Cientifico y Literario de Toluca fue construido hace ciento cincuenta años, por José María González Arratia, en lo que era el Beaterio de Muchachas Recogidas de los Carmelitas. Otro magnífico edificio de este género es el Instituto de Ciencias y Artes de la ciudad de Oaxaca (1899).

$24 \mathrm{De}$ los múltiples ejemplos existentes de escuelas suntuosas podrían citarse la José Manzo, de Puebla; el Antiguo Liceo de Niñas en Guadalajara (Lucio Gutiérrez 1897-1898; hoy, Palacio de Justicia); la Escuela Preparatoria de Jalapa, con un magnífico salón de actos neorococó; etcétera, etcétera. 
fue sino una utilización a posteriori de un edificio destinado en su origen a otros fines, como se verá más adelante.

Pero si en estos rubros la arquitectura mexicana no ostenta ejemplos señeros, no ocurre lo mismo con el teatro. Recreado como programa arquitectónico específico en la época del humanismo, el concepto del teatro oscilaria, durante los siglos siguientes, entre el espectáculo de elevada significación humana y el despliegue fastuoso de prodigios escenográficos, visuales y auditivos, como a su vez lo concibe el barroco; entre la experiencia profundamente formativa que quisieron los ilustrados, y el pretexto para la vida de relación social y el exhibicionismo jerárquico, como fue visto desde una perspectiva más frívola.

La época ilustrada nos ha dejado un ejemplo interesante en el Teatro Alarcón de San Luis Potosí, proyectado por Francisco Eduardo Tres. guerras (1825-1827), obra tardía que en su clasicismo híbrido no sólo parece anticipar el eclecticismo de finales del siglo sino que permite asimismo apreciar la libertad con que los arquitectos provincianos, más alejados y ajenos al purismo académico y el respeto por la morfología clásica, van a lanzarse por el camino de la invención bizarra, lo que da a sus obras mucho de su encanto pintoresco y caprichoso, como puede apreciarse en las eclécticas obras de un Refugio Reyes, por ejemplo.

A mediados del siglo se construyen otros teatros, como el de la República en Querétaro (obra de Camilo San Germán, de 1845-1852) y el Teatro Nacional, en la capital (proyecto de Lorenzo de la Hidalga). En estos proyectos se evidencia el gusto por las formas italianizantes, neorenacentistas, que se impone por aquellos años y viene a añadirse, junto con otras posibilidades estilísticas, al clasicismo imperante hasta entonces. Con estás obras neorrenacientes, y las primeras neogóticas, puede decirse que se inicia, tímidamente, el eclecticismo en México, que vendrá a culminar en la rica diversidad de las obras porfiristas, en especial las realizadas después de 1890 .

Quiero aprovechar esta coyuntura para subrayar algo que juzgo importante: existen dos momentos muy señalados en la historia de la arquitectura decimonónica mexicana en que parecen haberse concentrado, bien los intereses de los investigadores, bien, efectivamente, la actividad constructiva, en cantidad y, tal vez, en calidad. Estos dos momentos son, por supuesto el neoclasicismo de finales del xvur y primer tercio del xix, y el eclecticismo porfiriano. Entre estos dos periodos parece extenderse un largo y oscuro paréntesis en que se antojara no ocurrir nada, o apenas muy poco, en nuestra arquitectura. Evidentemente, éstos 


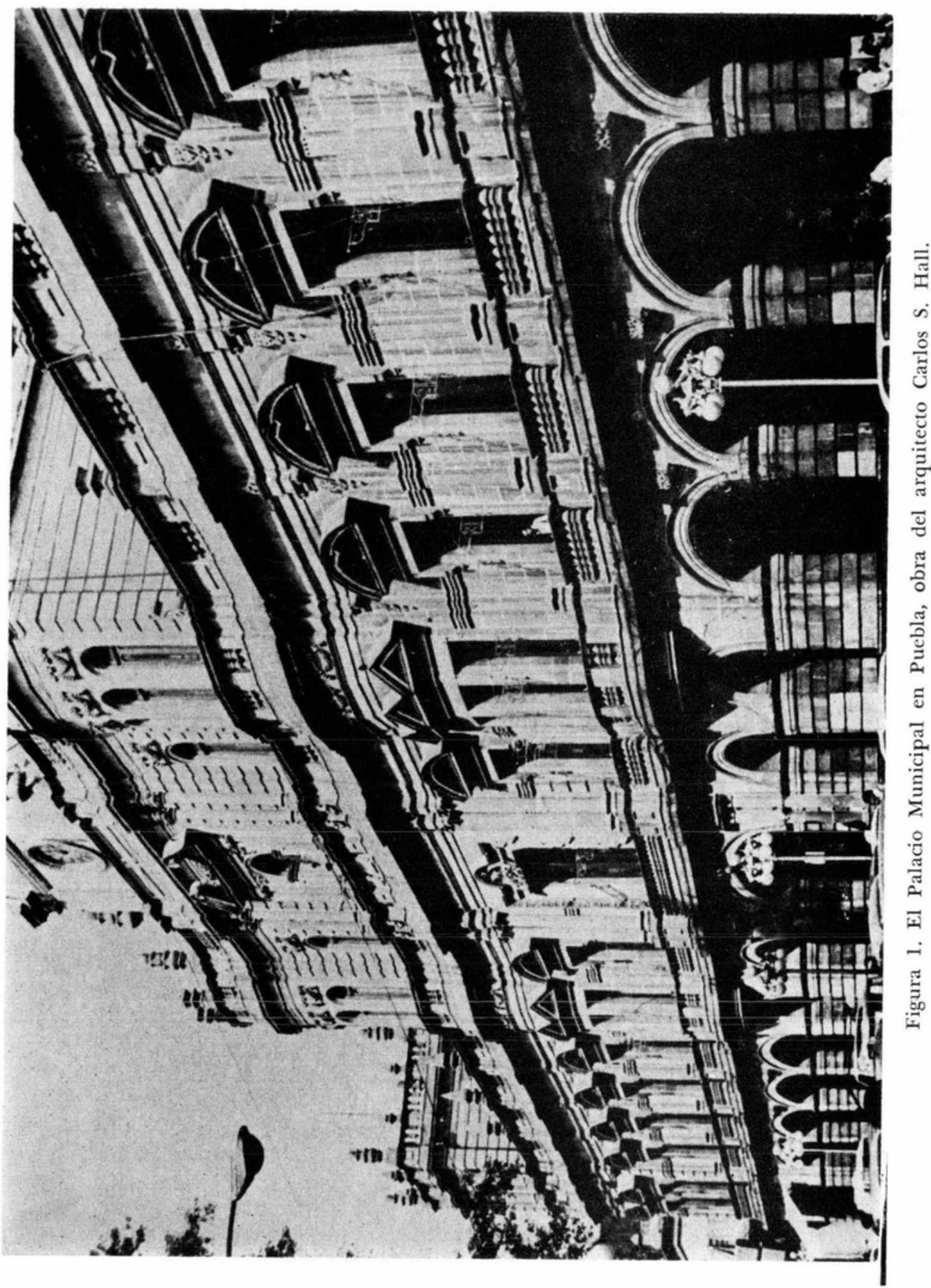




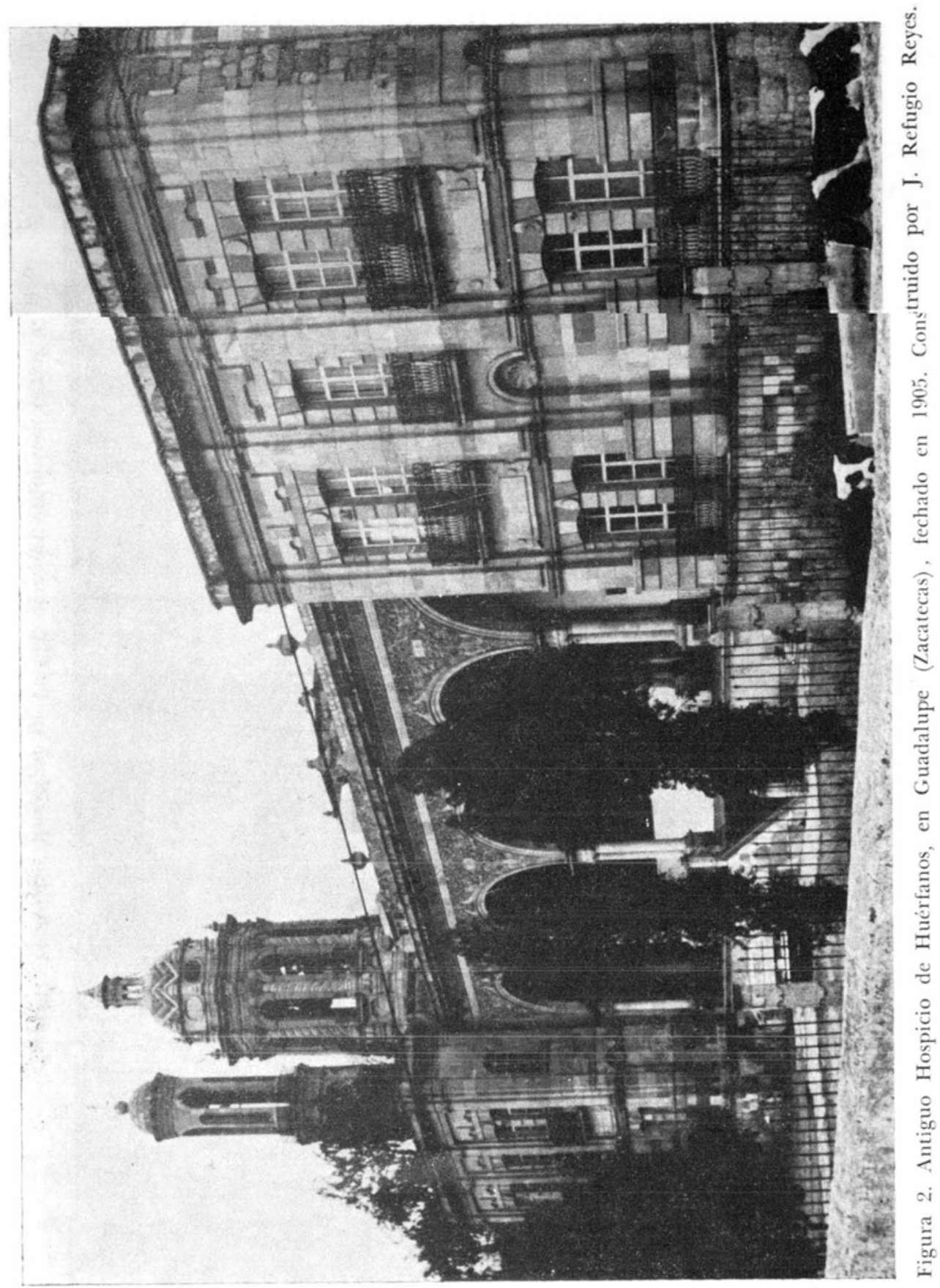




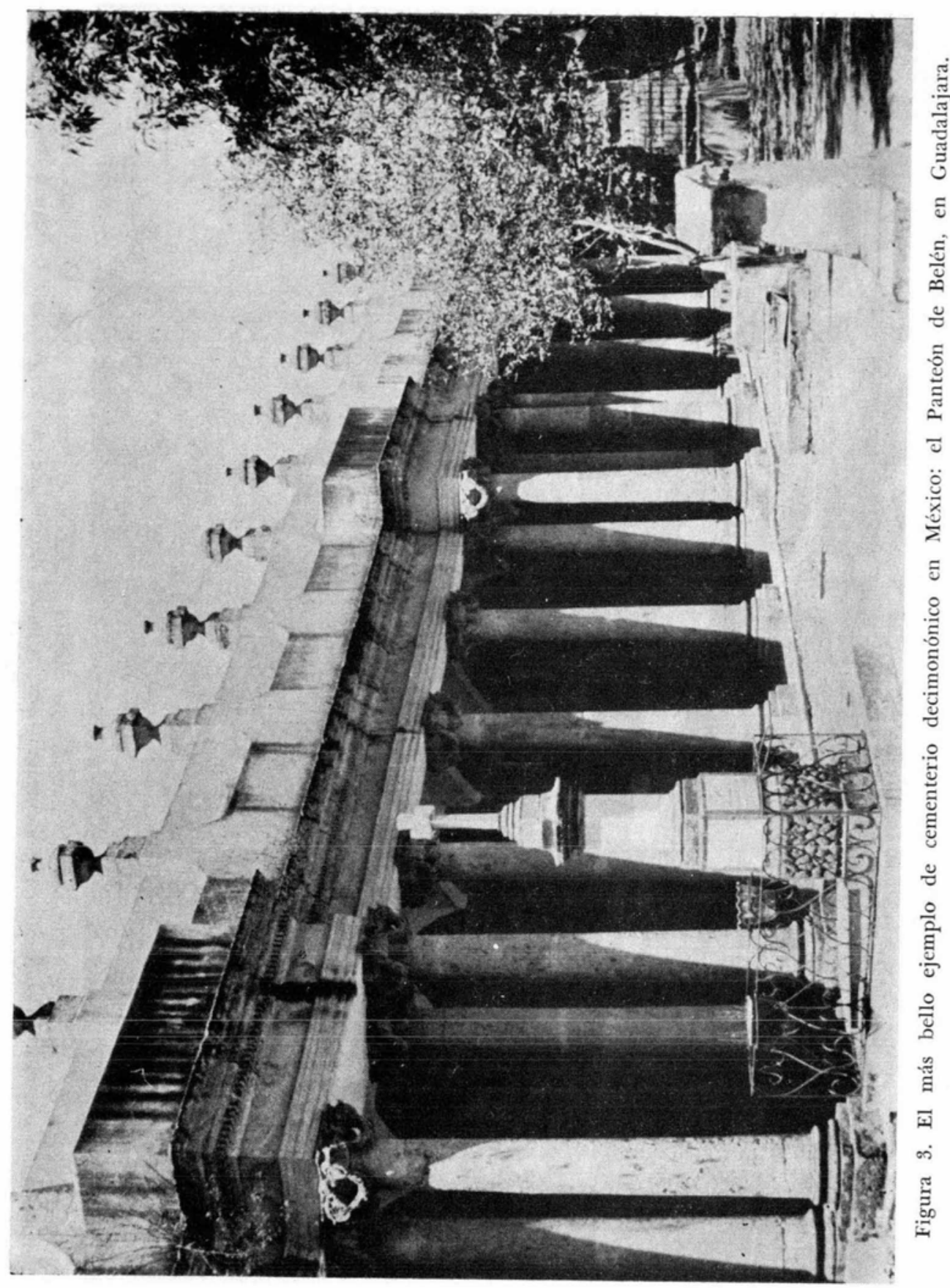




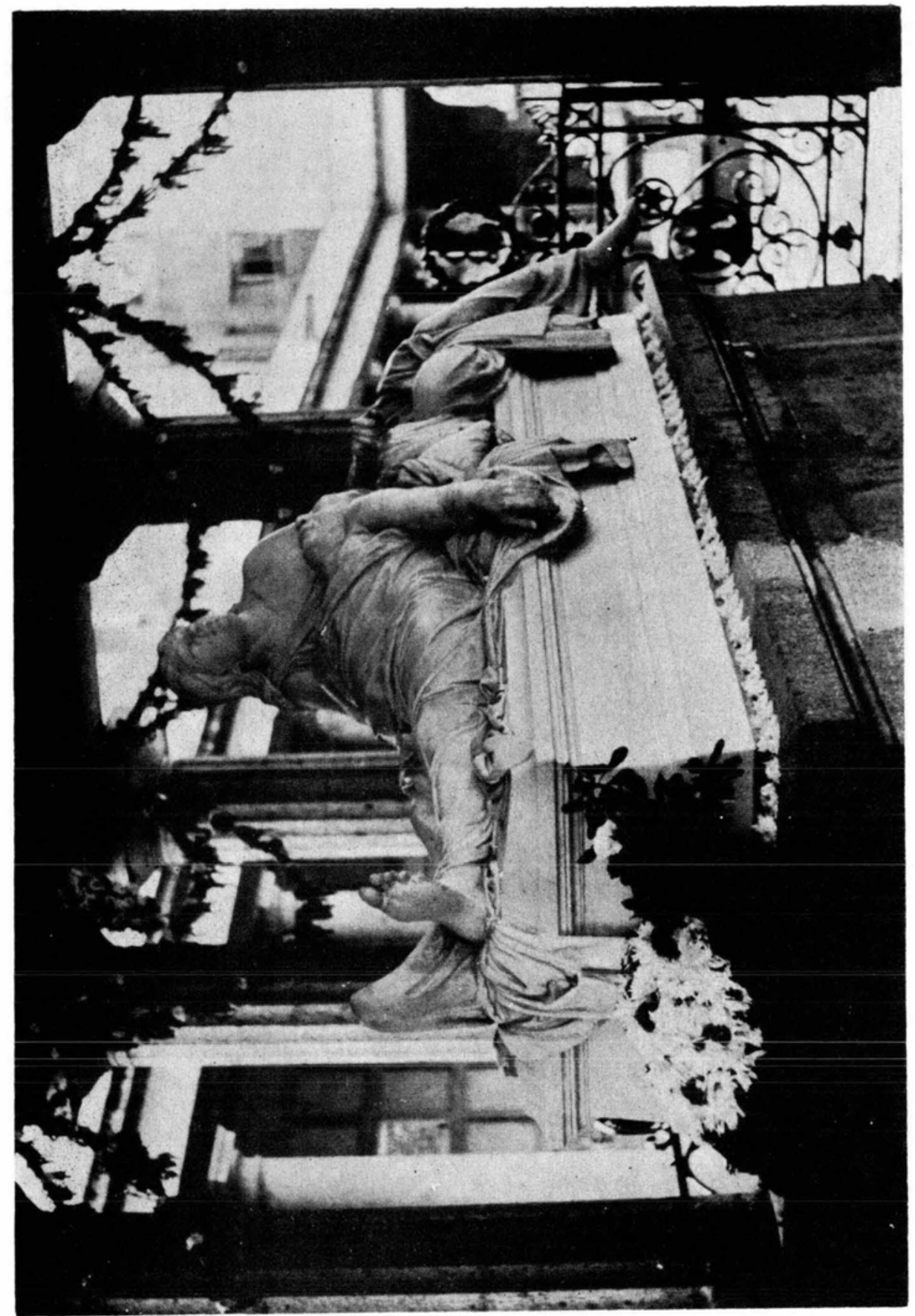




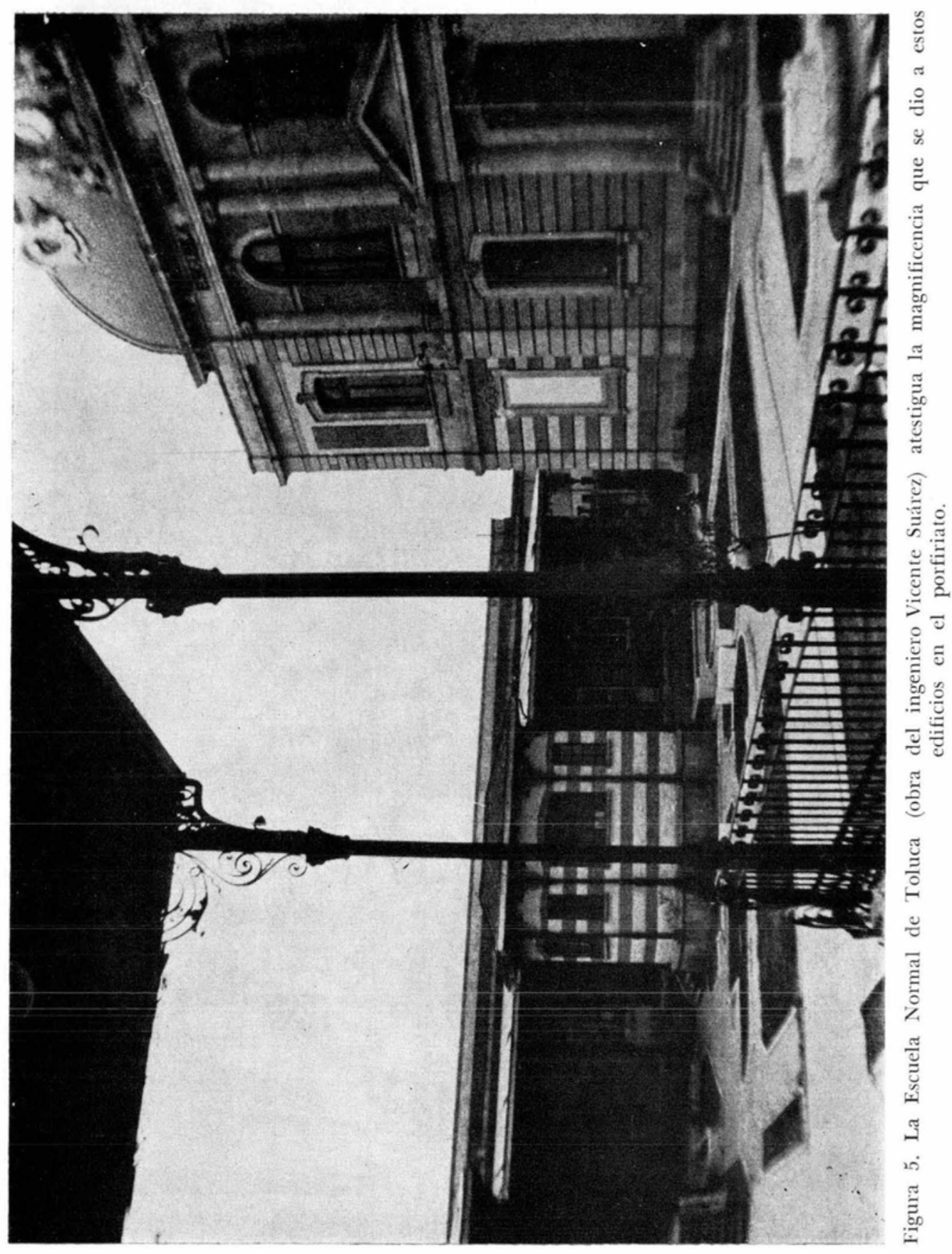


DOI: http://dx.doi.org/10.22201/iie.18703062e.1978.48.1102


Figuras 6 y 7. Dos suntuosas escuelas decimonónicas: la Escuela de la Torre, en Jerez (1894-1895) y la Superior para Señoritas, en Jalapa (1910). 
DOI: http://dx.doi.org/10.22201/iie.18703062e.1978.48.1102

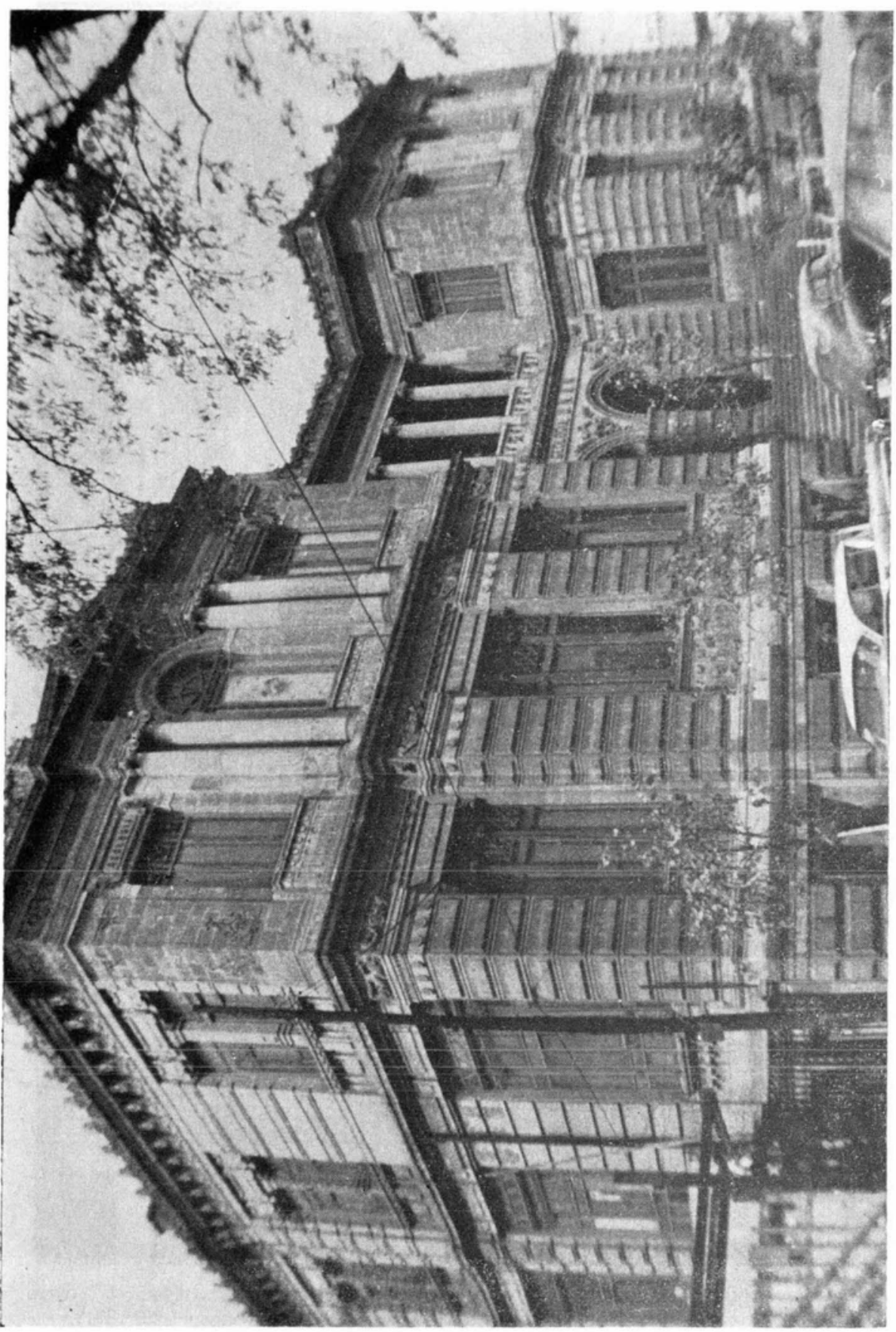

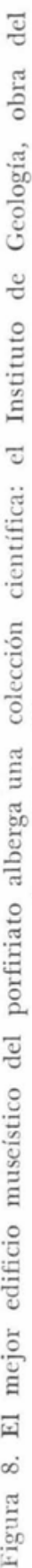




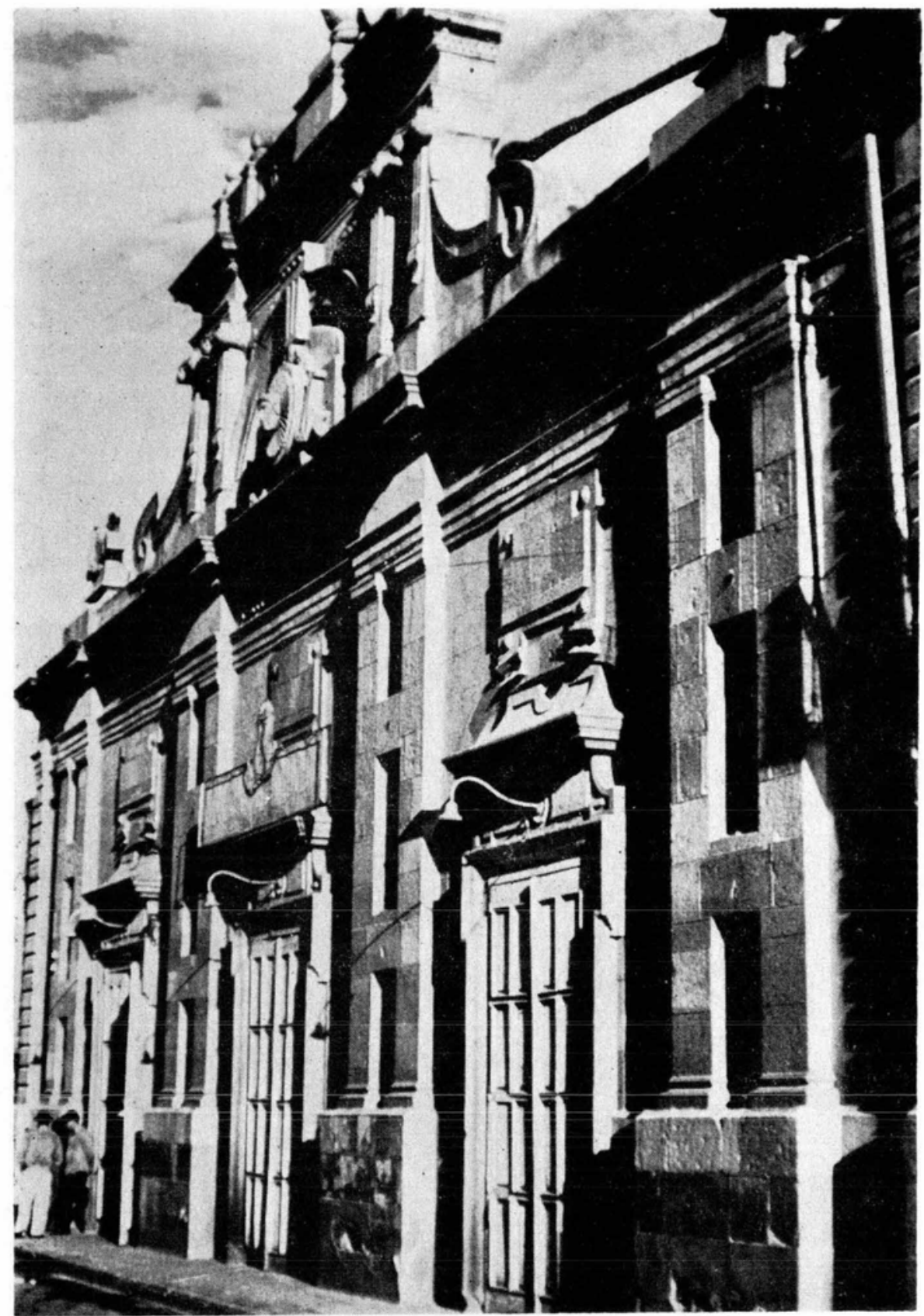

Figura 9. Un ejemplo temprano de arquitectura teatral y neomanierista: el Teatro Alarcón, en San Luis Potosí (Francisco Eduardo Tresguerras, 1825-1827). 
DOI: http://dx.doi.org/10.22201/iie.18703062e.1978.48.1102

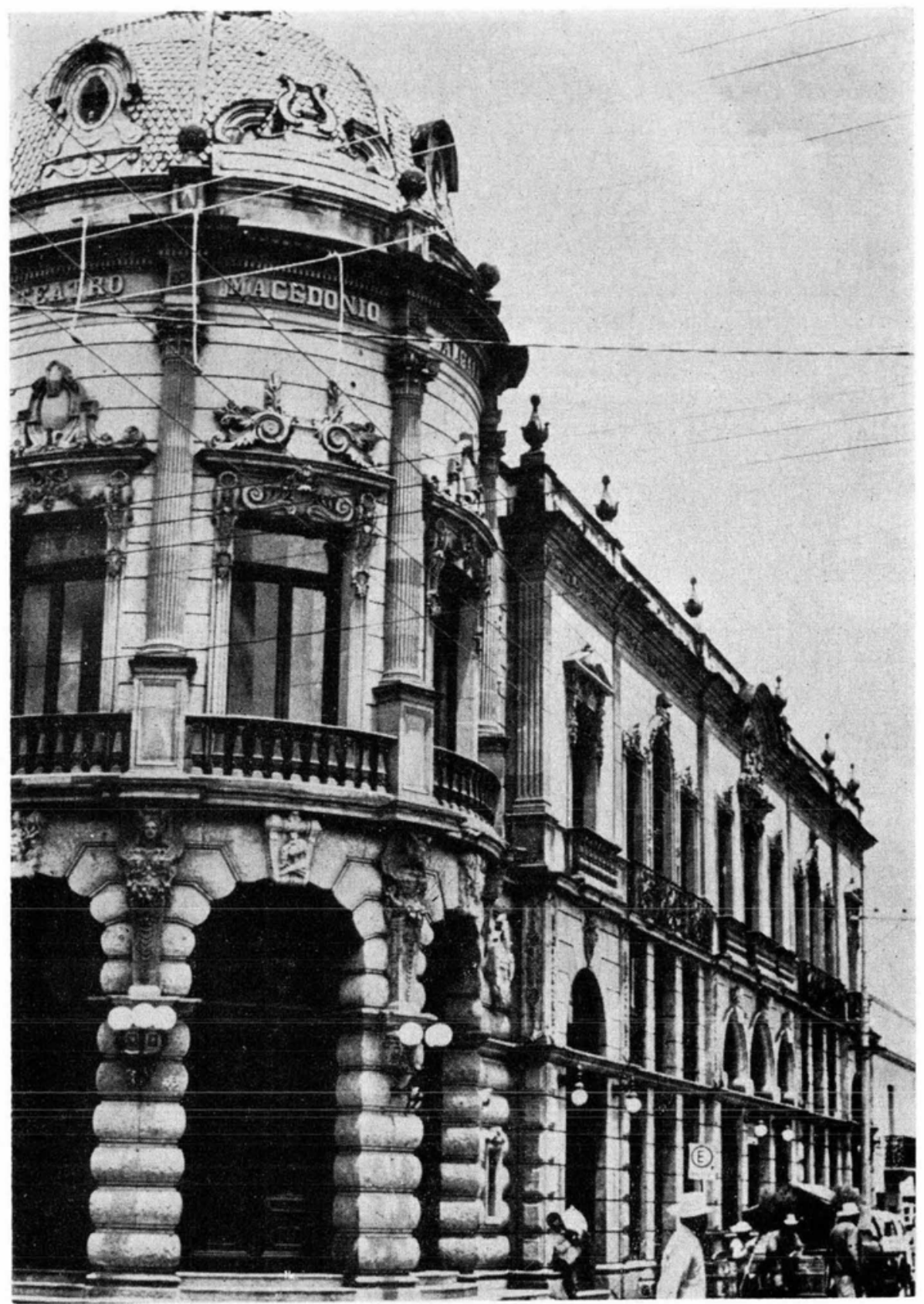

Figura 10. El Teatro-Casino Luis Mier y Terán (hoy, Macedonio Alcalá), en Oaxaca, construido por el ingeniero Rodolfo Franco en las postrimerías del porfiriato (1904-1909) . 
DOI: http://dx.doi.org/10.22201/iie.18703062e.1978.48.1102

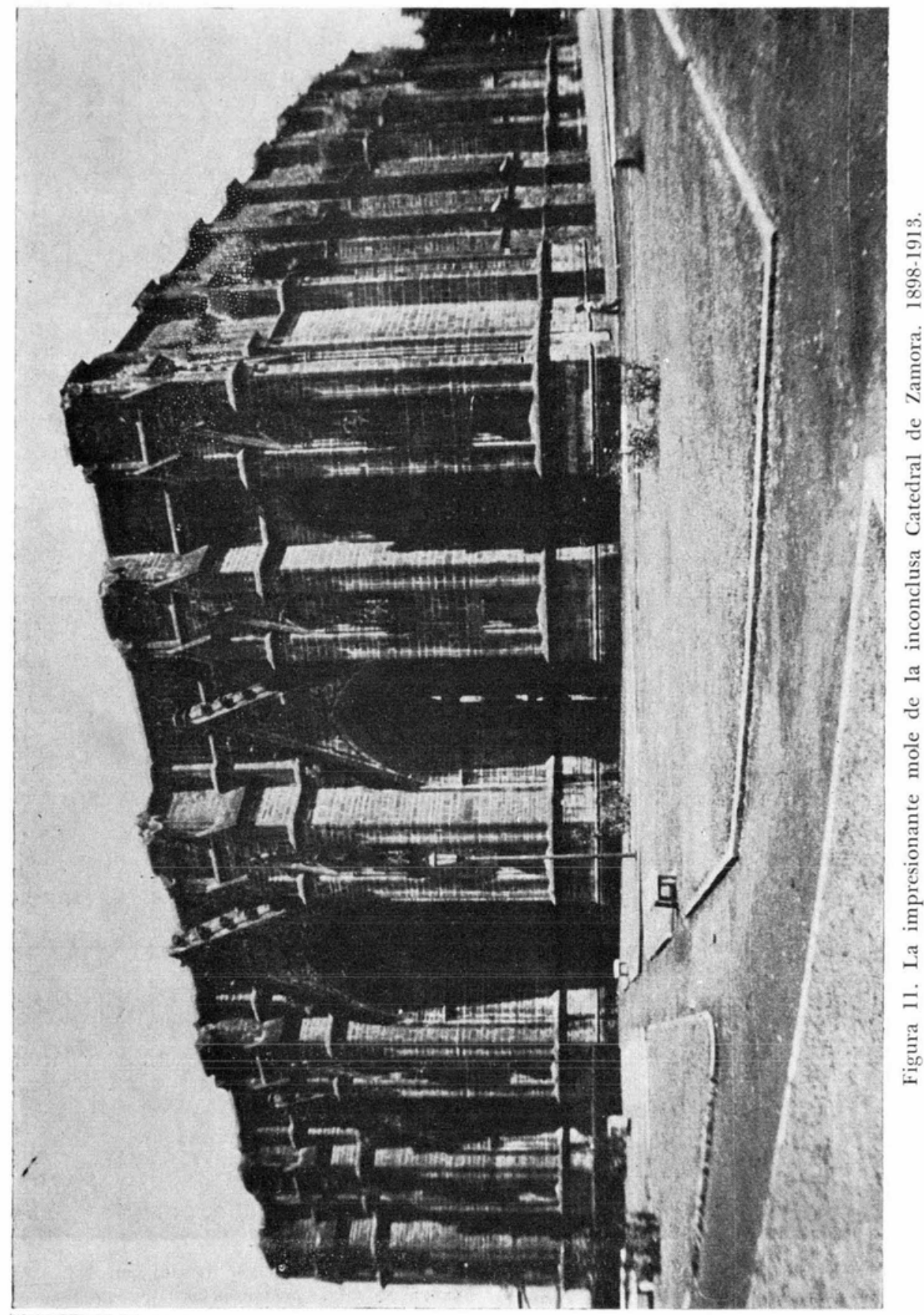


DOI: http://dx.doi.org/10.22201/iie.18703062e.1978.48.1102

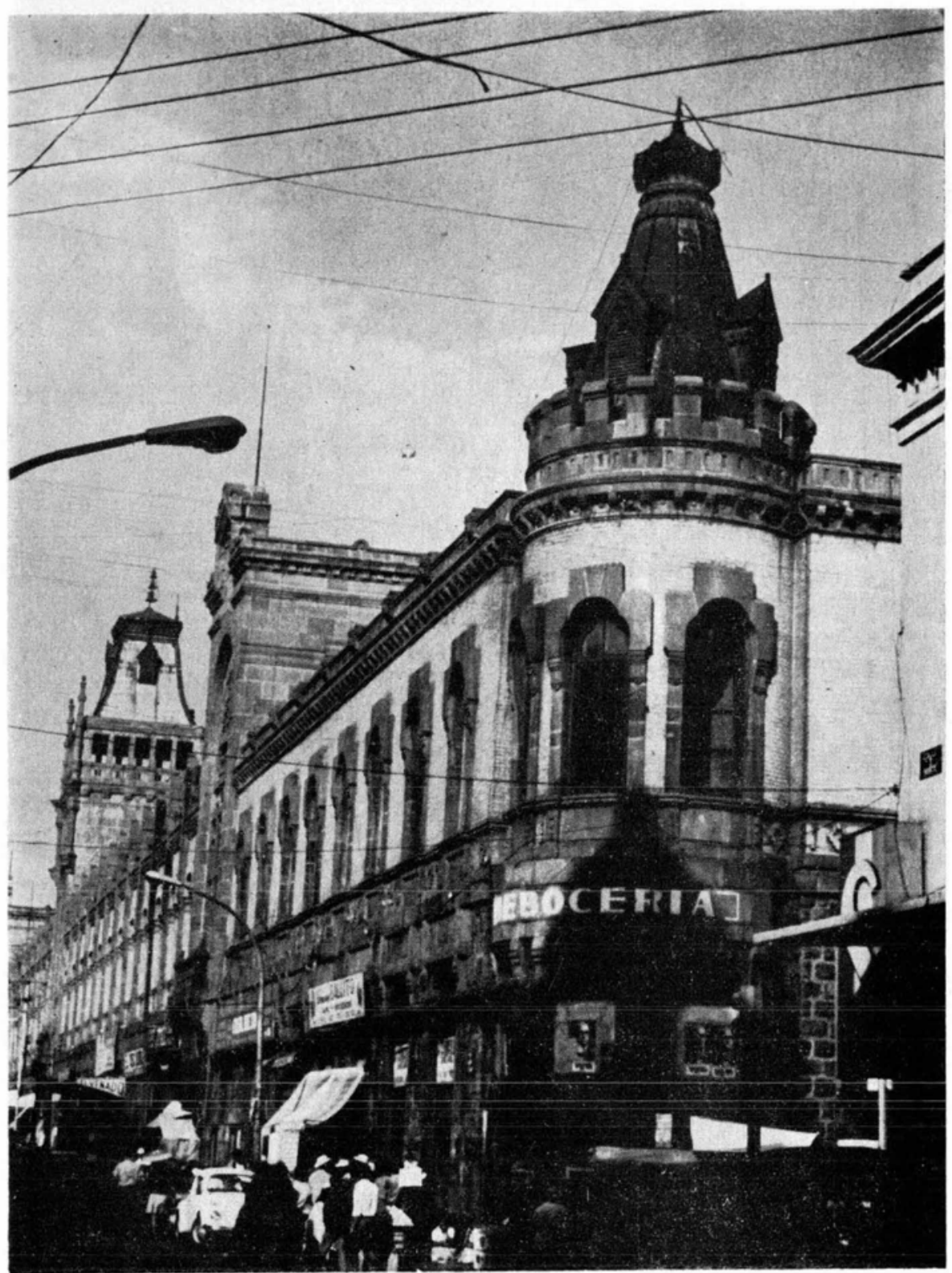

Figura 12. El Mercado de la Victoria, en Puebla, fue inaugurado el año de 1913: es uno de los más complejos programas de este géncro. 


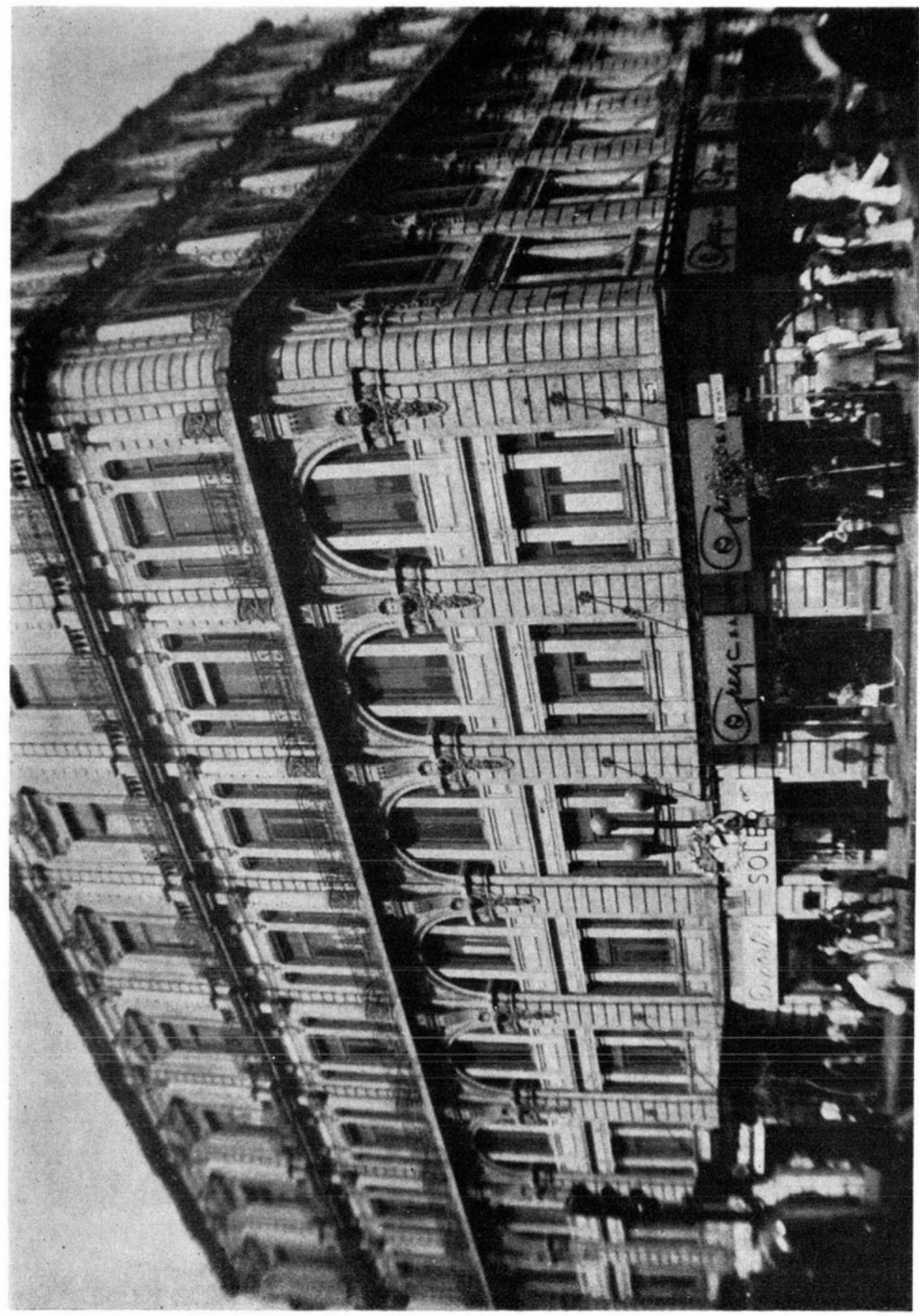




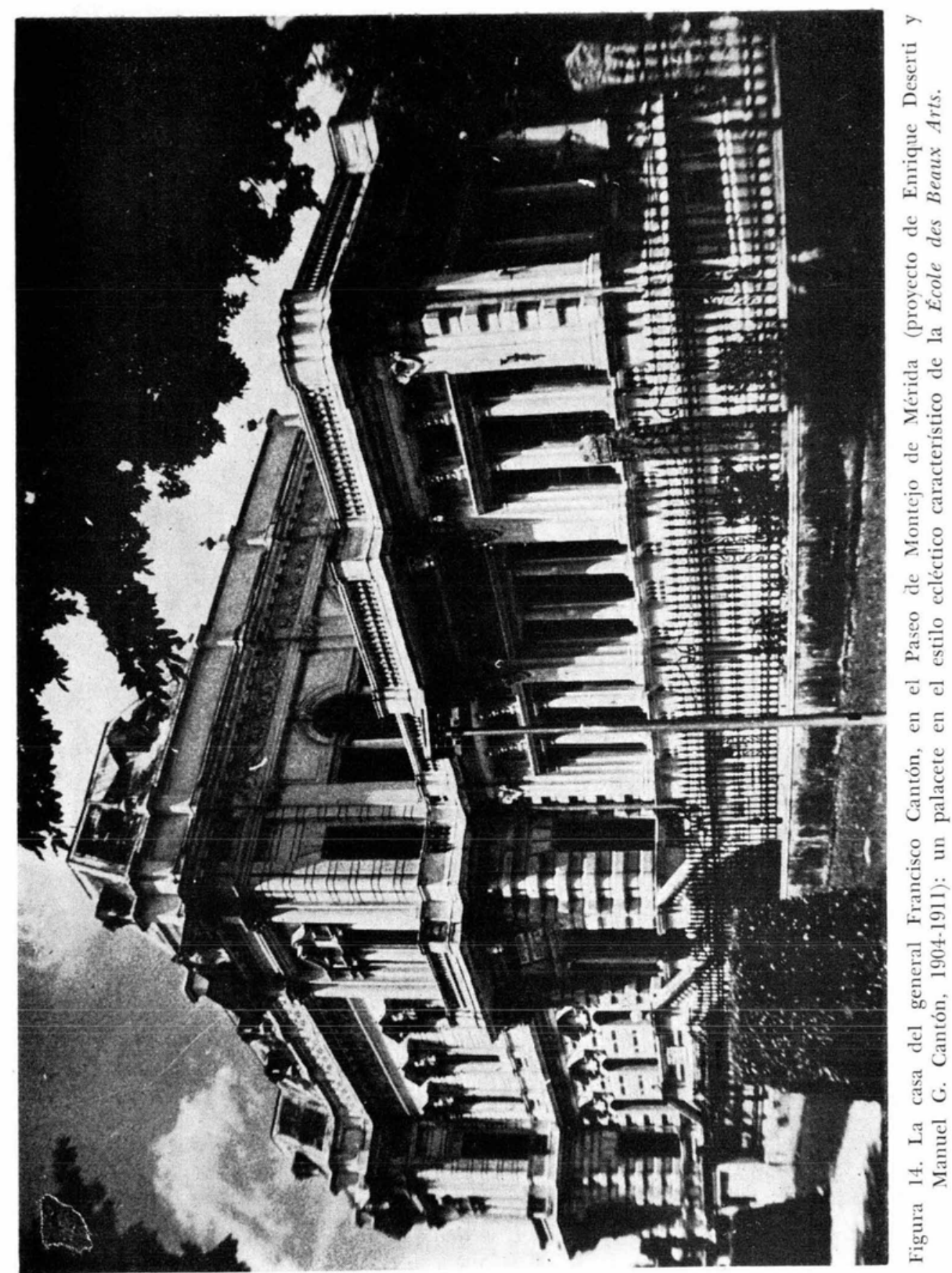


DOI: http://dx.doi.org/10.22201/iie.18703062e.1978.48.1102

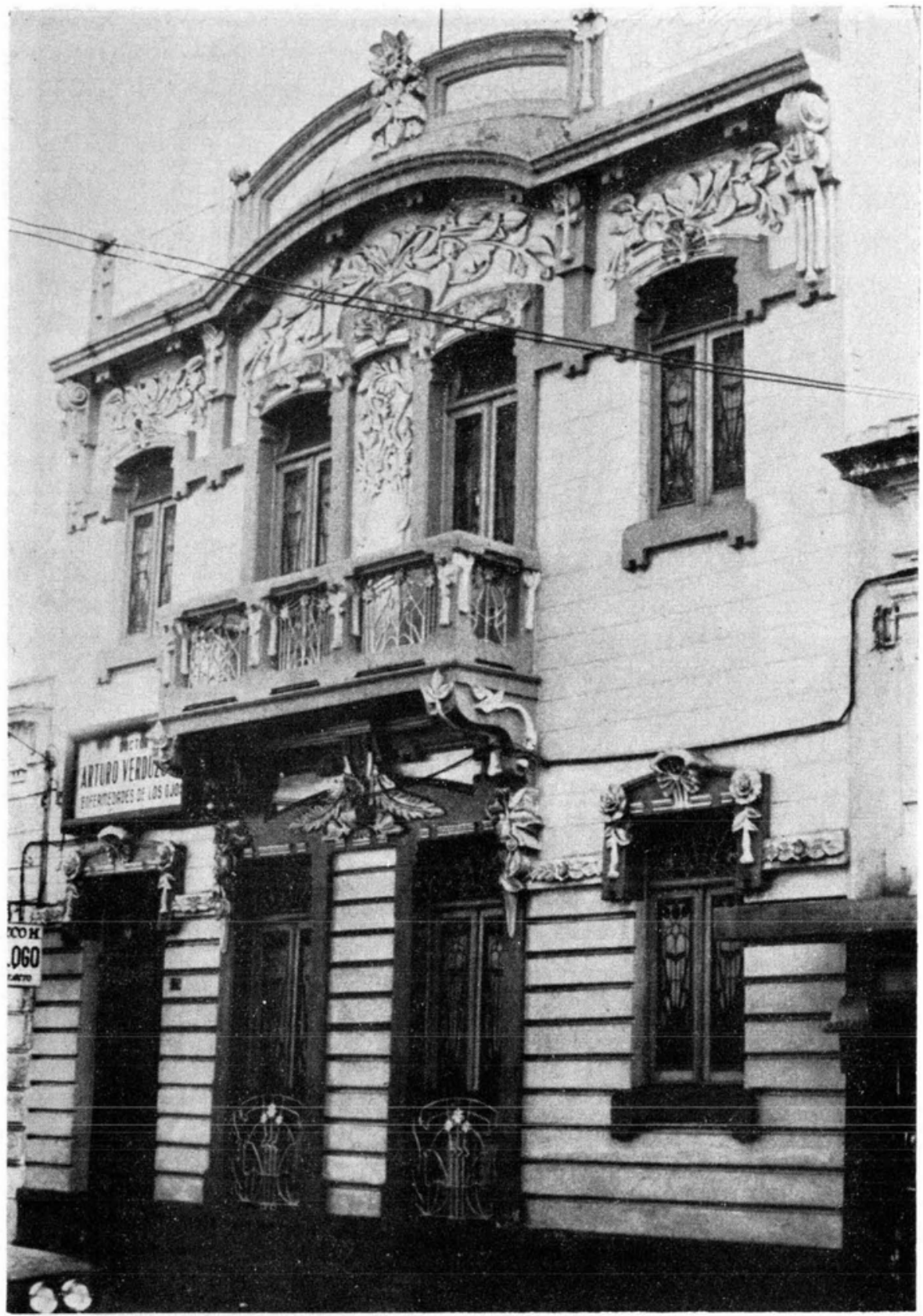

Figura 15. Fachada de casa en estilo Art-Nouveau, ubicada en López Cotilla 525, Guadalajara. 
DOI: http://dx.doi.org/10.22201/iie.18703062e.1978.48.1102

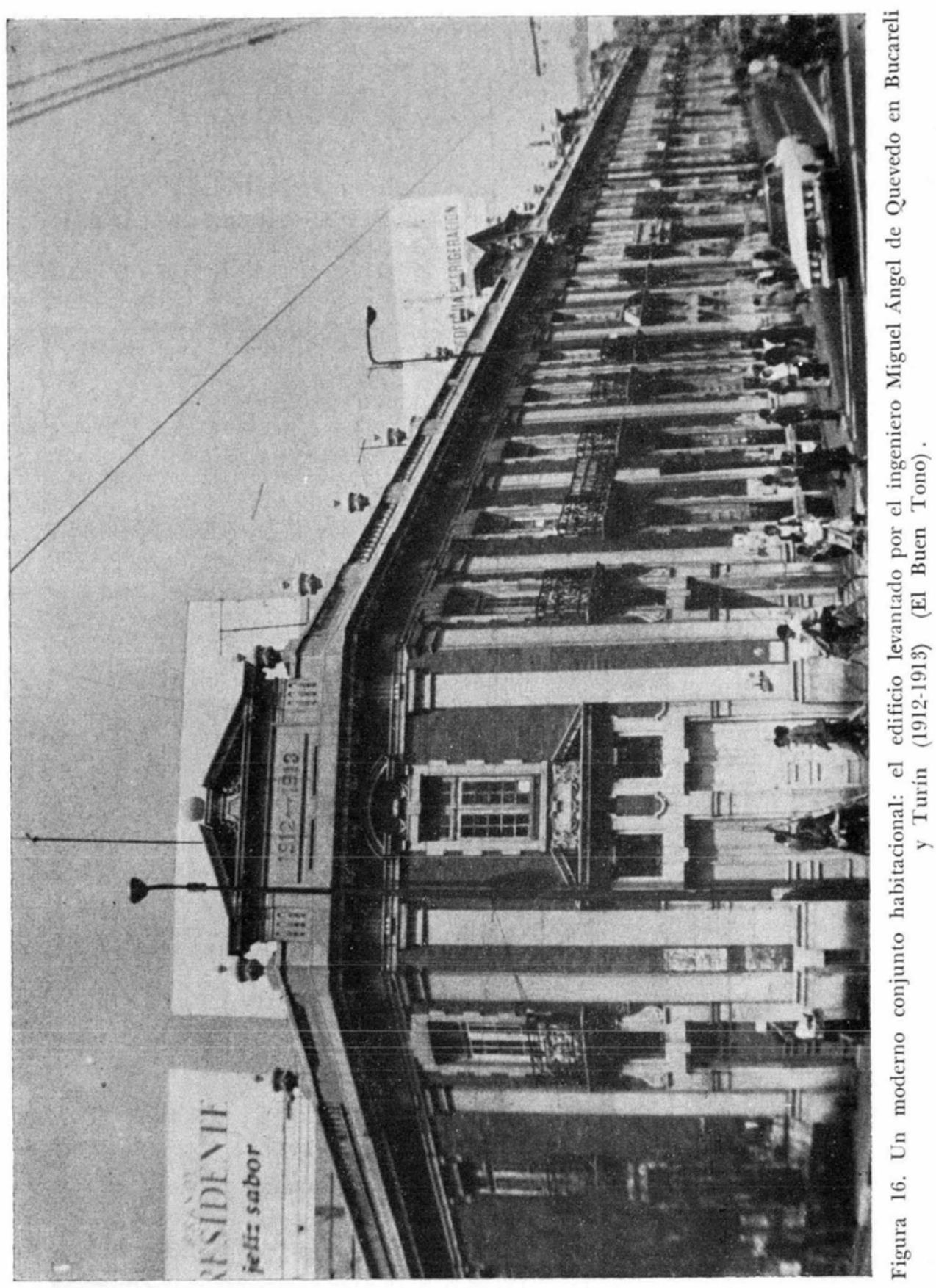




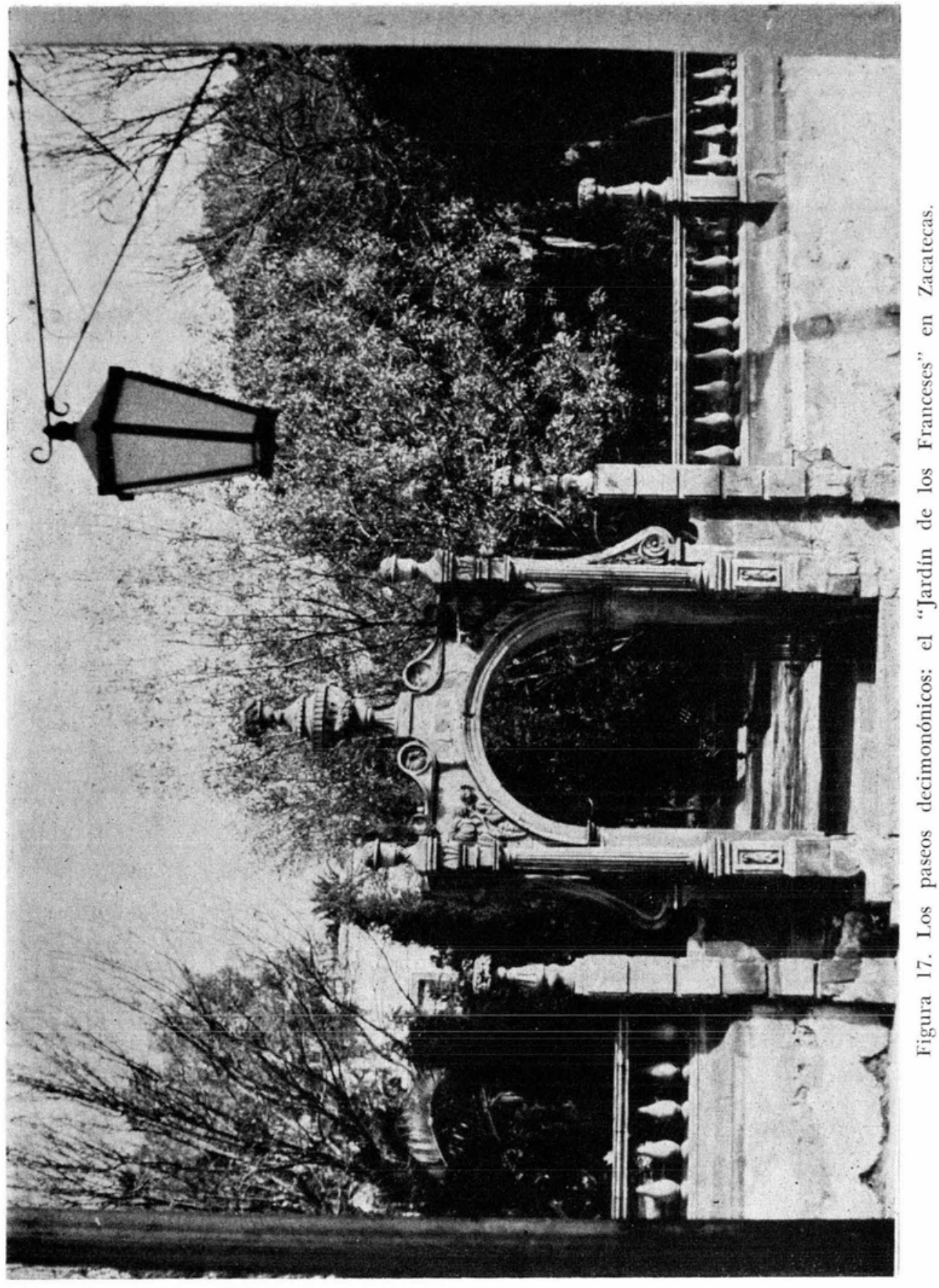




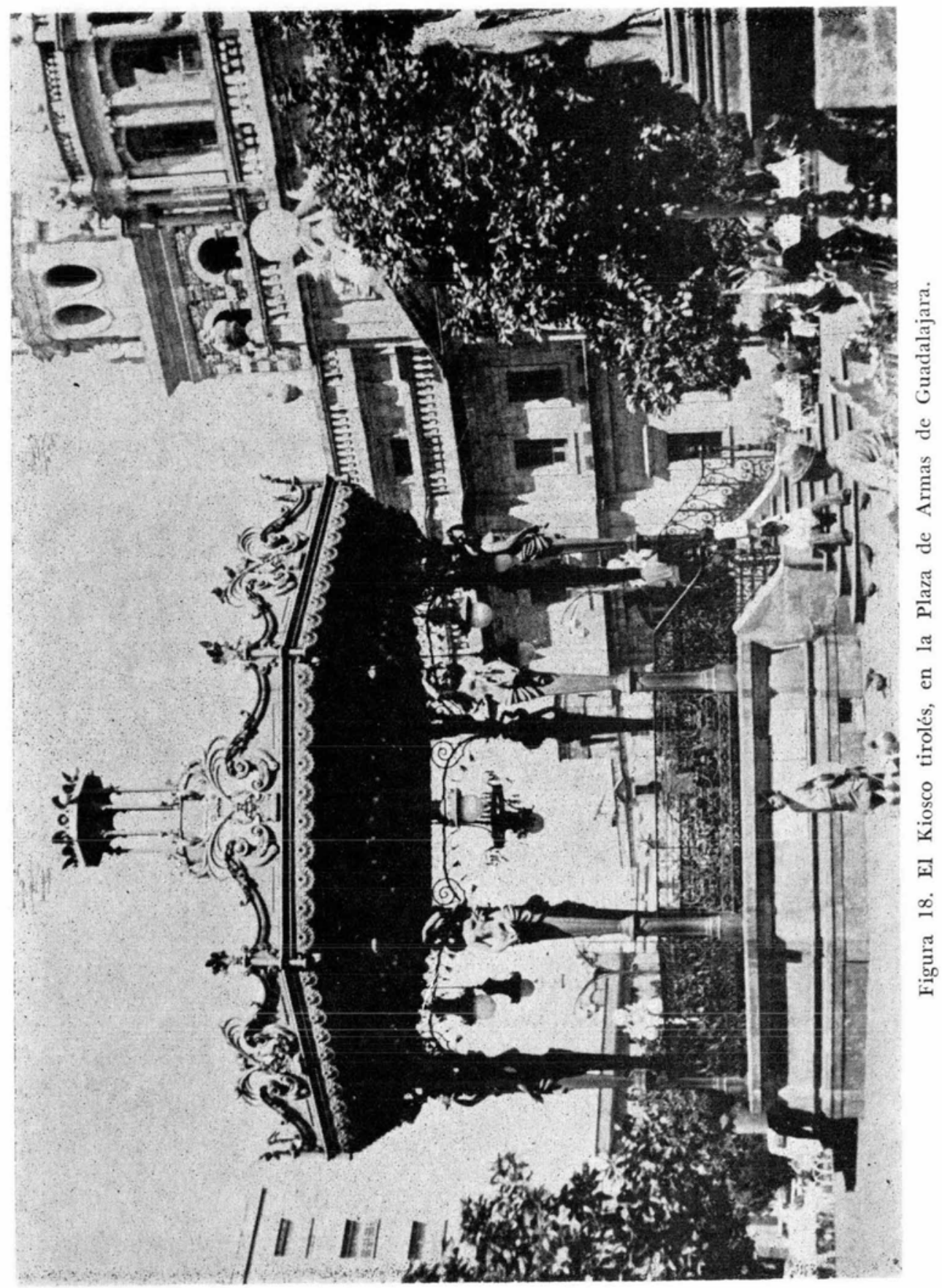


DOI: http://dx.doi.org/10.22201/iie.18703062e.1978.48.1102

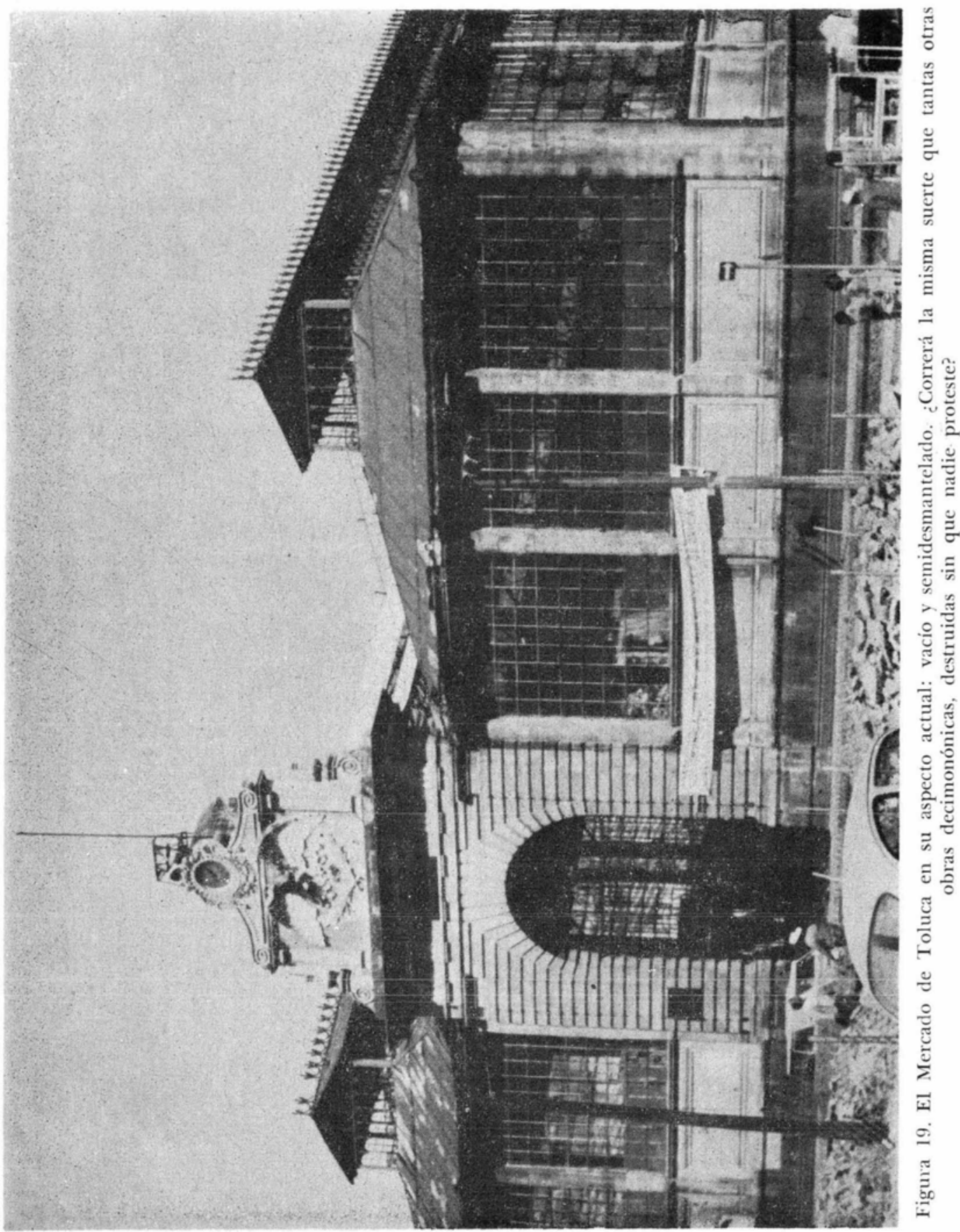


son los años de mayor inestabilidad política y tal vez por esto haya pocas obras oficiales señalables.

Creo, empero, que sufrimos un error de perspectiva al respecto, resultado de la falta de conocimientos especialmente grave para este tramo cronológico. Tenemos que admitir que hace falta una nómina completa de los arquitectos activos en esos años y, sobre todo, de las obras concretas que se realizaron. Que sí hubo edificios interesantes lo demuestran los teatros mencionados, o los Baños de los Arquitos en Aguascalientes. Habriamos de pensar, además, que la penetración en la provincia de los nuevos estilos (y, en concreto, del neoclasicismo), procede siempre, por lo general, a paso lento. Por tanto, muchas (la mayoría, me atrevería a afirmar) de las obras de este estilo dispersas en las ciudades y los pueblos del interior, en especial las iglesias, los retablos y las casas, deben haberse hecho precisamente en este periodo oscuro.

Tornando al teatro, podemos considerar como muestras características de la exuberante inventiva ecléctica en el apogeo del porfixiato, el Teatro Juárez de Guanajuato (obra de José Noriega y Antonio Rivas Mercado, 1892-1903) y el Teatro-Casino Macedonio Alcalá (antes Luis Mier y Terán) de Oaxaca (construido por Rodolfo Franco, 1904-1909).

Como un paréntesis, aprovechando el doble carácter de teatro y casino que tenía el coliseo oaxaqueño, tomo pie para referirme a los casinos, importantes instituciones en la vida de relación decimonónica, cuando se disponía de muchas más horas libres que en la actualidad, horas que había que matar agradablemente en compañía de un grupo, social o nacional, con el cual se identificaba el asociado y en cuya compañía jugaba, leía, comía, conversaba o festejaba, por lo cual el casino debía disponer de salones adecuados para todos estos diferentes propósitos.

El espléndido Casino Español de la capital (1903), encabeza la lista, en la que hay que incluir otras muestras de casinos provincianos (el de la Laguna, en Torreón, por ejemplo). Habríamos de ccisiderar también, como muy próximos a este rubro, edificios como el del Círculo Católico en Puebla (hoy, Congreso del Estado), con funciones comparables de vida de relación e identificación grupal, el cual ofrece un ejemplo extraordinariamente suntuoso de teatro semiprivado, que nos remite a la práctica de representar comedias, usual entre las "buenas familias" porfiristas, siempre y cuando se limitara esta afición al ama teurismo y a los círculos restringidos, justificándose muchas veces so pretexto de recabar fondo para obras pías. Finalmente, se puede relacionar 
con este género de edificios, los que albergaban a las sociedades mutualistas que proliferaron desde mediados del siglo pasado. ${ }^{25}$

Volviendo a las salas de espectáculos, podrían aducirse muchos otros ejemplos de teatros "profesionales", desde los monumentales levantados en las ciudades más señaladas (Guadalajara, Zacatecas, Veracruz, Mérida), hasta los menos pomadosos, como el delicioso y rústico teatro de Jerez, Zacatecas.

Además de los "aparatos ideológicos del Estado", Althusser se refiere a los "aparatos represivos". Cuando la conformación ideológica del individuo falla e incurre en acciones que salen fuera de los límites permisibles por la sociedad y el Estado, se hace intervenir otros expedientes para reprimirlo o sancionarlo. Ejército y policía se encargan de salvaguardar el orden por la fuerza; cárceles y manicomios se levantan para aislar y castigar a los insumisos.

Tenemos así cuarteles y delegaciones policiacas, como la muy notable Sexta Delegación o Inspección de Policía, de la calle de Revillagigedo, construida por Federico Mariscal (1906-08) en estilo neogótico (jinvoluntaria asociación de indole oscurantista?) , y las penitenciarías de Puebla (José Manso y Eduardo Tamariz, 1844-1886), Mérida (Salvador Echegaray, 1902) o la de Lecumberri, las tres de aspecto imponente y sombrio, que suscitan desde el exterior una impresión de aislamiento y terror.

No resultará extraño considerar, junto al presidio, el manicomio, pues es evidente que, haciendo abstracción de otras causas de la perturbación enajenante, el loco representa al individuo cuyo comportamiento rebasa los márgenes impuestos por la sociedad y consagrados con el calificativo de to "normal", como punitiva consecuencia de lo cual se le separa y confina en un universo muy semejante al carcelario. No se conserva ya el más importante de los asilos para enfermos mentales levantados en el siglo xix, el de la Castañeda (obra de los ingenieros Porfirio Díaz, Ignacio de la Barra y Carlos Noriega, 1908-1910). ${ }^{26}$

En cuanto a las iglesias, se suele censurar el aspecto tan poco "espi. ritual" que presentan las del siglo $\mathrm{xrx}$, si se las compara con las de los siglos barrocos. Pienso que esto es el resultado de otro error de perspectiva. Las iglesias neoclásicas, con sus claras líneas geométricas, sus

25 Véase el edificio de la Sociedad La Unión, en Mérida (fundada en 1857), o los edificios de las sociedades mutualistas poblanas.

26 Lo que fuera el pabellón del director de La Castañeda se halla actualmente reconstruido, como villa campestre, cerca de Amecameca. 
superficies blancas y su carencia de oros, colores y retorcimientos, muestran un deseo de sustraer lo religioso del plano eminentemente emocional que acentuara el arte barroco, para colocarlo también en el nivel de las experiencias racionalizables. Se abandona el misterio en favor de la lucidez, lo cual es perfectamente válido. ${ }^{27}$..

Algunas iglesias decimonónicas, como la del Buen Tono, producen una impresión de salones de reunión comunitaria un tanto "profanos", en cuanto que carecen de asociaciones de índole mística o irracional. Pero esto presenta una notable semejanza con algunas de las ideas contemporáneas posconciliares acerca de la planeación eclesial y les confiere un carácter anticipatorio interesante. ${ }^{28}$

Otras más, en fỉn, recurren a las asociaciones espirituales que suscitan los estilos medievales, como el románico o el gótico, que si bien es cierto que no cuentan con antecedentes originales en nuestro pais $y$, por tanto, no responden a una tradición "genuina", sí ofrecen en sus proporciones y en su disposición formal ese impulso ascensional que tan bien sugiere la fuerza de la oración, independientemente de si se conocen o no las formas y el sentido originales del estilo. ${ }^{29}$

Habría que mencionar, por último, algunos ejemplos neobarrocos, que se dieron a finales del siglo pasado y a principios del presente; sea un barroco en sentido más local, como podría ser la capilla de Nápoles, anexa a la iglesia de Villa de Guadalupe, Zacatecas, sea en las originales invenciones del maestro Refugio Reyes, en la iglesia de San Antonio de Aguascalientes.

Palacios arzobispales (como el de Oaxaca, construido durante la larga gestión del obispo Gillow y hoy convertido en palacio federal) y casas curales (como la de Abasolo, 1896) son, por supuesto, edificaciones civiles sólo relacionadas con lo eclesiástico por el carácter profesional de sus ocupantes.

El desarrollo de la industria moderna supuso la creación de programas

27 Ejemplos célebres de templos neoclásicos: Loreto (Castera y Paz, 1809-1816), San Pablo (Antonio González Velázquez); el Carmen de Celaya y Las Teresas de Querétaro (F. E. Tresgnerras); el Sagıanio de Guadalajara (José Gutiérrez y Manuel Gómez Ibarra, 1808-1843), etcétera.

28 Así lo señaló Manuel Sánchez Santoveña en conferencia del 25 de octubre de 1977, en la Universidad Iberoamericana.

29 Existe un número tan elevado de iglesias neorrománicas y neogóticas en el país que puede afirmarse, en verdad, que estos estilos han adquirido carta de naturalización, en el ánimo del mexicano practicante, para significar el espíritu de oración. Casi no existe ciudad que no cuente con obras de estilo neomedieval. 
novedosos relacionados con la producción, el almacenamiento, el transporte, la distribución y el consumo de la mercancía.

Dadas las condiciones de dependencia bajo las que se incorporó México al proceso mundial del capitalismo (en particular cuando, durante el último cuarto de siglo, éste ingresa a su fase imperialista), la economía del país se orientó más bien hacia la extracción de materias primas y la producción agropecuaria, en ambos casos con la mira de exportar los productos hacia las grandes metrópolis del capital, de las cuales se importaban, a la vez, los artículos elaborados. De ahí que prácticamente no exista en el México decimonónico la industria pesada o de transformación. Había buen número de fábricas, pero relacionadas con determinados ramos de la producción, como los hilados y tejidos, la fabricación de cigarros, cerveza, vidrio, etcétera.

Un ejemplo venerable y precursor fue la Real Fábrica de Tabacos, fundada a finales del virreinato y construida por Antonio González Velázquez, la cual inaugura una tradición de edificio industrial de gran magnificencia, que habremos de encontrar un siglo después en muestras igualmente prestigiosas, como la Fábrica de Cerveza de Toluca y México, espléndido edificio del 1890 . Otros ejemplos, en cambio, son modestos y en ellos se acentúa más bien el carácter utilitario de las estructuras.

Debemos considerar también, entre las instalaciones de carácter productivo, las haciendas, núcleo de la producción agropecuaria, sobre las que se ha acumulado - no siempre con justicia- mucho del desprestigio y la ignominia caídos sobre el régimen porfirista, razón por la que difícilmente se libraron de la destrucción revolucionaria. Con todo, las muestras que se conservan no dejan lugar a dudas acerca de su importancia como programa arquitectónico. Los cascos de hacienda del Estado de México, por ejemplo, con sus grandes dimensiones (muchas veces sin genuina utilidad práctica) y su aspecto estilístico (eminentemente culto y ajeno al ámbito rural), señalan la implantación del poderío económico urbano sobre el campo. ${ }^{30}$

La circulación de mercancias requirió medios de transporte más rápidos y eficaces, que permitieran mover económicamente grandes cantidades. Las materias primas extraídas de las minas, los productos agropecuarios, etcétera, debían llegar con facilidad a las costas y fronteras para ser

30 Asf lo atestiguan, por ejemplo, la fábrica neogótica de la Hacienda de Suapayuca (1876), o las sugerencias palladianas que evocan los pórticos columnados de las haciendas de Nexquipayac y Tepejalpa. 
embarcados a los centros hegemónicos del capital. Los artículos importados, a su vez, habían de ser distribuidos con presteza hacia el interior. La solución fue construir vías férreas. Su distribución en el país es muy reveladora de la situación dependiente de nuestra economía, primero con respecto de las metrópolis europeas, más tarde en relación con los Estados Unidos.

Vias férreas supusieron estaciones de ferrocarril, de paso y terminales. Construcciones por lo general de ladrillo y piedra, más bien sencillas, como acceso a andenes resueltos a base de ligeras estructuras férreas. ${ }^{31}$

Con esto entramos a la otra gran posibilidad estructural desarrollada en el siglo xIx, la arquitectura de hierro, usada de la manera más original y creativa para determinar, no las construcciones cerradas y macizas de bloques pétreos o de ladrillo, sino estructuras abiertas y ligeras en que interior y exterior se relacionan dinámicamente. Fue el tipo de estructura requerida para determinados edificios como, por ejemplo, mercados y pabellones de exposición, en los cuales era indispensable cubrir vastas superficies con techos leves, hechos de material que soportara los esfuerzos de tensión, para lo cual el fierro funciona en forma muy superior a la piedra.

La construcción de mercados fue muy abundante en México. El mercado decimonónico, a base de crujías altas y aireadas, todas cubiertas, sustituye al tipo de mercado claustral, del que el Parián colonial de la ciudad de México fuera ejemplo. En estos mercados es interesante observar el uso de la piedra o el ladrillo como material exterior, para delimitar (muchas veces con suntuosidad y delicados efectos de detalle) los espacios internos, ritmados y techados por esbeltas estructuras metálicas, que ofrecen un agradable contraste con la maciza envolutra. ${ }^{32}$

Los pabellones de exposición integran otro capítulo importante y muy característico de la arquitectura del siglo xix, relacionado estrechamente con el desarrollo de la industria y la mentalidad consumista que lleva consigo el capitalismo contemporáneo. En las grandes capitales de

21 Por asociación con la idea del viaje y la facilidad de desplazamiento fomentada por los ferrocarriles y el mejoramiento de los caminos, mencionemos de paso la construcción de hoteles en sentido modeıno, que vienen a sustituir a los antiguos mesones. El Hotel Central de Morelia, por ejemplo, se construyó en el sitio del Mesón de San Agustín. Refugio Reyes proyectó y levantó varios hoteles en Aguascalientes (Francia, París, Escobedo).

32 Recordemos, entre la gran profusión de mercados decimonónicos esparcidos por todo el país (algunos de los cuales están desapareciendo), el de Guanajuato (Ernesto Brunel, 1909-1910), el de Zacatecas (Refugio Reyes), el Mercado de La Victoria, en Puebla y el hoy amenazado mercado de Toluca. 
los centros hegemónicos europeos (Londres, París) y norteamericanos (Chicago, Filadelfia) empezaron a organizarse, a partir de 1851, exposiciones adonde concurrían las diversas naciones del globo para mostrar sus productos. Eventos de emulación y competencia productiva, fundamentalmente, las exposiciones internacionales aspiraron, asimismo, a convertirse en el muestrario ideal del progreso y de la posibilidad de bienestar y felicidad puramente mundanos, a que se aplicó la cultura europea a partir de la Ilustración. Despliegue de la fantasía aunada a la ciencia y la técnica, cosmos onírico en el que pareciera que un paraíso terrenal, instaurado aquí y ahora, hubiese sustituido al de la bienaventuranza espiritual hasta entonces buscado, las exposiciones universales del fin de siglo resumen ideales y realidades entrañablemente amadas por el optimismo decimonónico.

Con Porfirio Díaz, se siente la necesidad de que el país organice ferias nacionales y participe en los eventos internacionales, adonde se enviaban muestras de nuestros productos, requiriéndose edificaciones ad hoc para su exhibición. De los pabellones construidos en distintas ocasiones conocemos dibujos, alzados, fotografías, como la curiosa estructura neoindigenista que constituía el pabellón mexicano en la exposición de París de 1889 (proyecto de Antonio M. Anza, asistido por el arqueólogo Antonio Peñafiel).

Se conservan dos estructuras importantes traídas a México, armadas aquí y destinadas a usos diversos del original: el kiosco morisco de la Alameda de Santa María, en su origen pabellón mexicano en la expo. sición de Nueva Orleans de 1884-1885, obra de Ramón Ibarrola. Y el que fuera por muchos años Museo de Historia Natural del Chopo, y que trajera a México de Düsseldorf (Alemania) el señor José Landero y Cos con el propósito de montar una exposición permanente de productos industriales y artísticos locales y foráneos. Montado por Luis Bacmeister, sirvió de pabellón para la exposición de productos presentados por la delegación japonesa en ocasión de las fiestas del Centenario, después de lo cual se le destinó a albergar las colecciones de historia natural, a partir de $1915 .{ }^{33}$

Para el consumo interno se requirieron tiendas. Existian las tiendas destinadas a vender una sola línea de productos, que fueron resueltas arquitectónicamente de acuerdo con el viejo modelo de cubículos abiertos en la planta baja de un edificio, cuyo piso superior sirve de habitación;

33 Datos proporcionados por la señora Dora Aguilar, quien está por concluir su tesis de licenciatura (Hitoria del arte, Universidad Iberoamericana) sobre este tema. 
o bien, con una solución nueva, en edificios grandes y lujosos, construidos exprofeso para ser ocupados en su totalidad por una casa comercial, como la Casa Boker (De Lemos y Cordes, 1898) o la Joyería de la Esmeralda (José Francisco Serrano y Eleuterio Méndez, 1890-1892).

Pero donde la pasión por el consumo fue fomentada y sublimada al máximo es en las monumentales "tiendas de departamentos", en donde se vendía toda suerte de productos, expuestos a los ávidos ojos de los consumidores en un despliegue entre festivo y museográfico. Majestuosos edificios de varios pisos, resueltos en torno a un vasto pozo central, a base de estructuras metálicas marcadas al exterior por órdenes colosales, que velaban en parte el esqueleto férreo, y por airosos remates cupulares que, a la manera de los viejos campanarios, atraían la atención de los viandantes y proclamaban jovialmente el triunfo del comercio, presidiendo la vida contemporánea. ${ }^{34}$

Finalmente, habríamos de mencionar que, con el desarrollo de la economía moderna, se hizo cada vez más perentorio contar con edificios para la banca y también con edificios de oficinas para las firmas e instituciones mercantiles, grandes y pequeñas, y para despacho de los profesionistas. Esto trajo consigo la proliferación de semejante tipo de estructuras por las calles céntricas de las ciudades, y que van desde el modesto edificio de dos pisos que perpetúa la vieja tradición de fundir oficinas y casa habitación en uno; hasta los edificios especializados de varios pisos, característicos de la tendencia moderna, resueltos con estructura de metal que, sin embargo, no solía dejarse evidente, recubriéndosela bajo fachadas historicistas. ${ }^{35}$

Demos el paso, ahora, de lo público a lo privado: de los edificios de indole gubernamental o comercial, a las residencias particulares. Los géneros y soluciones de la casa son tan variados como lo pueden ser, por un lado, la diferente jerarquía en la escala económica del ocupante, su personalidad individual y social, sus recursos y su voluntad de aplicarlos; por otro lado, los diferentes estilos que se ofrecían al gusto del arquitecto y el cliente como base de la solución formal de la obra,

34 Por desgracia, muy pocos son ya los edificios mercantiles que no hayan sido destruidos o trasformados (a veces para usos totalmente diferentes) "No sabemos, por ejemplo, qué ocurxirá con el que fuera La Ciudad de México en Puebla (ca. 1908). San Luis Potosí conserva, funcionando, el de El Palacio de Cristal.

$35 \mathrm{La}$ calle del Cinco de Mayo ostenta varios edificios de esta indole. Destaco, por ejemplo, el Edificio París, obra del arquitecto e ingeniero José Francisco Serrano, 1906-1907. 
las determinaciones climáticas y de carácter regional, el color, la textura y la calidad de los materiales asequibles, etcétera.

El tema es tan amplio que renuncio a comentarlo más, y será suficiente consignar la riqueza de soluciones adoptadas por el arquitecto decimonónico desde la residencia palaciega neoclásica de finales del virreinato, ${ }^{36}$ hasta los palácios de la aristocracia porfirista, en sus distintas posibilidades: la solución académica, tipo Ecole des Beaux Arts, ${ }^{37}$ o ciertas formas más caprichosas, como la pintoresca villa que tanto prolifera en determinadas colonias de la capital y la provincia (la Roma de México o la Reforma de Guadalajara).

La casa más modesta se construía de piedra o, cuando esto no era posible por escasez de recursos económicos o carencia regional del material adecuado, de ladrillo y yeso, los que dieron resultados magníficos (Guadalajara es rica en ejemplos). Mucha falta hace un estudio especial de esta arquitectura doméstica menos permanente, antes que el tiempo y la incuria acaben por destruirla.

Los edificios de apartamentos, herederos muchos más pomadosos de nuestra antañona casa de vecindad colonial, comenzaron a levantarse en las nuevas colonias hacia finales del periodo considerado. ${ }^{38}$

Quiero concluir con una última reflexión.

Al visitar y vivir nuestras ciudades, en especial aquellas que aún conservan con mayor o menor fidelidad el aspecto que tenía la generalidad de las urbes mexicanas antes que un detestable (por mal entendido) afán de "progreso" contemporáneo viniera a destruirlas irreparablemente, debemos pensar que adquirieron su fisonomía en el siglo pasado. Nuestras ciudades, en general, están constituidas por unos cuantos ejemplos (dónde más, dónde menos) de fábricas coloniales dispersas en un contexto sustancialmente decimonónico. Es admirable la armonía que guardan estas dos arquitecturas: en proporciones, ritmos, morfología, colores y texturas, nunca o casi nunca choca un edificio porfirista con uno virreinal, antes

36 Como los palacios construidos por Manuel Tolsá (el de Buenavista y el del Marqués del Apartado) o la casa del Conde de Casa Rul, en Guanajuato, diversamente atribuida (T'Tresguerras, Tolsá).

37 Para citar ejemplos no capitalinos, el Palacio Cantón ( $\boldsymbol{E}_{\text {. Deserti }}$ y Manuel G. Cantón, 1904-1911) y el Palacio Cámara, en el Paseo de Montejo de Mérida, o las casas en la calle de Reforma de Puebla, o las construidas por Carlos de Alba, en Guadalajara (Av. Madero y 16 de Septiembre o $A v$ Madero y Colón), etcétera, etcétera.

38 Por ejemplo, el edificio en Bucareli $161-189$ y Turín, obra del ingeniero Miguel Ángel de Quevedo (1912-1913), o el Edificio Vizcaya en la propia calle de Bucareì 128; el edificio en la Plaza Río de Janeiro y Durango, etcétera. 
por el contrario, se determina una unidad en la variedad verdaderamente notable.

Las grandes obras de urbanización, la ampliación de las ciudades y el trazo de nuevas calles y colonias ${ }^{39}$ fueron obra del siglo pasado. Pero también aquello que se refiere a obras de infraestructura urbana, como alcantarillado, drenaje, suministro y tomas cie agua, alumbrado, etcétera; trazado de bulevares y alamedas, parques y jardines; erección de fuentes, kioscos y relojes, portales y pasajes: todo lo que suministra y constituye el marco exterior en que transcurre la vida urbana, es legado del siglo Xix,

Así pues, el concepto decimonónico de la ciudad preside las relaciones sociales de la colectividad en aquellos lugares donde no se ha destruido la vigencia de una vida de trabazón comunitaria, vale decir, en la provincia.

El siglo XIx, pues, no sólo originó la aparición de programas nuevos, inéditos y sin precedentes. Creó, asimismo, todo este enmarcamiento en el cual no sólo podemos reconocer y esclarecer el origen de nuestra modernidad, el arranque mismo de nuestro ser actual, sino también la posibilidad de sentimos parte integrante de una colectividad: regional y nacional. Preservar esta posibilidad me parece particularmente significativo. Aquí radica la verdadera importancia de la arquitectura decimonónica, y la razón última para que nos preocupe su salvaguarda.

39 Las Leyes de Reforma ejercieron una apreciable influencia sobre el trazo urbano de nuestras ciudades. Las expropiaciones y demoliciones para abrir nuevas calles y plazas a través de los predios conventules, nos recuerdan que la lucha con el poder eclesiástico se libró no sólo en el plano legal sino también en el simbólico-visual. 